\title{
MANAGING SWITCHING COSTS IN MULTIPERIOD PROCUREMENTS WITH STRATEGIC BUYERS*
}

\author{
By TRACY R. LEWIS AND HuSEYIN YILDIRIM ${ }^{1}$ \\ Duke University, U.S.A.
}

\begin{abstract}
This article examines the use of switching costs by long-lived strategic buyers to manage dynamic competition between rival suppliers. The analysis reveals how buyers may employ switching costs to their advantage. We show that when switching costs are high, a buyer may induce suppliers to price more competitively by credibly threatening to replace the incumbent supplier with his rivals. The implications of this finding for adoption of technology and firm organization are explored in settings in which the buyer is integrated with the suppliers and where the buyer is an outsourcer.
\end{abstract}

\section{INTRODUCTION}

"Switching costs," "lock in," "tipping," "penetration pricing," and "compatibility" are some colorful terms that describe market competition in today's hightechnology economy and in some traditional manufacturing sectors. The genesis for these terms comes from the fact that purchasers may incur significant costs of switching from one good or service to another. Real switching costs arise because (i) buyers may require training to use a new technology or good, (ii) buyers may incur setup or transactions costs to consume the new service, or (iii) buyers may lose compatibility of use with others who employ a different service. ${ }^{2}$ A classic example occurs when a company switches from using one type of computer equipment or software to another. Changing computer service requires employees to learn new routines, to reconfigure hardware and software to be compatible, and to reestablish communication networks with other users, all of which are time consuming and costly activities.

Given the prevalence and significance of switching costs in many markets, it is important to understand how they impact upon consumers' welfare and affect

\footnotetext{
* Manuscript received October 2003; revised August 2004.

${ }^{1}$ We are indebted to Paul Klemperer for his insightful and most helpful comments on an earlier draft of the article. In addition, we wish to thank Nicola Persico and two anonymous referees for their assistance in revising an earlier draft, and Mark Armstrong, Rich Gilbert, Phil Haile, George Mailath, Bentley Macleod, Steve Matthews, John Riley, Tom Ross, Larry Samuelson, Carl Shapiro, and Eric Talley, and seminar participants at Koc, New York, Northwestern (Kellogg), Sabanci Universities, as well as the Universities of California (Los Angeles and San Diego), Florida, Pennsylvania, Southern California, Texas (Austin), Washington, and Wisconsin for their comments. All errors are ours. Please address correspondence to: Huseyin Yildirim, Department of Economics, Duke University, Box 90097, Durham, NC 27708. Phone: (919) 660-1805. Fax: (919)684-8974. E-mail: yildirh@econ.duke.edu.

${ }^{2}$ Unreal or artificial switching costs created by frequency of use pricing, such as frequent flyer programs, are also borne by consumers who switch services.
} 
the behavior of producers and overall performance in these market. Beginning with Klemperer's (1987) first and fundamental analysis of switching cost economics, an important literature, summarized in Klemperer (1995) and Farrell and Klemperer (2004), has emerged to examine these issues. Farrell and Klemperer (2004) demonstrate the intertemporal nature of price competition when there are switching costs. In the short term, buyers benefit from lower prices that suppliers offer to "lock in" consumers to their product. However in the long term, once locked in, this installed base of customers are socked with higher prices reflecting the costs of switching to competing goods. This "bargain then rip-off" pricing is not per se harmful to consumers if it only shifts the flow of consumer surplus forward in time. However, Farrell and Klemperer (2004) conclude that switching costs generally, though not always, do harm consumers by reducing price competition, deterring efficient entry, and reducing product selection and heterogeneity.

These conclusions suggest that buyers capable of affecting market outcomes would attempt to avoid switching costs whenever possible and otherwise minimize the costs and dislocation arising from switching products. Although this is an obvious matter to confirm, it is not directly addressed by the extant switching cost literature that focuses its analyses on passive individual buyers who behave as nonstrategic price takers. ${ }^{3}$

In this article, we take the analysis a step further by examining the optimal response of strategic buyers to switching costs. The procurement setting in which large power buyers are capable of affecting the terms of trade with suppliers is most appropriate for our analysis. Specifically, we envision a procurer who buys goods from competing suppliers repeatedly over time. Each time the buyer switches from one supplier to another she may incur a switching cost. These costs arise because the buyer must acquire skill at using a new supplier's product, and additionally she may lose her skill in operating the incumbent producer's product she has discarded. This loss of skill is a cost the buyer may incur in the future if she switches back to the original product. We permit the buyer to respond to these switching costs in several ways. First, she may act ex ante to reduce the anticipated costs of switching. The buyer can adopt a flexible production technology allowing her to change inputs at small costs, by selecting alternative suppliers who produce compatible products that are easily substituted for each other, or by training her staff to adapt to different productive inputs. We describe these strategies in greater detail in the following sections. Second, the buyer may pursue ex post strategies to manage switching costs by conditioning purchase prices on the extent to which she becomes locked in to a certain supplier. The buyer may bargain for a price reduction from an incumbent supplier if she expects to become locked into that producer in the future.

Our analysis reveals that very different pricing strategies may arise when buyers strategically manage their procurements to control switching costs. Specifically the

\footnotetext{
${ }^{3}$ Notable exceptions are the papers by Greenstein $(1995,1997)$ and Cabral and Greenstein (1990) who examine the response of government procurement of computer systems to switching costs. These papers offer some interesting observations from the investigation of government procurement behavior, which valuably complements our theoretical work.
} 
"bargain followed by rip-off" pricing predicted in markets with passive consumers does not materialize with multiperiod procurements. Most significantly we find the aversion of procurers to switching costs predicted by models with price-taking buyers may be reversed. Procurers may benefit when switching costs are large. This is because large buyers employ the threat of switching producers as a means to acquire lower prices from incumbent suppliers. Once an incumbent is replaced, the likelihood he will be hired again to supply the procurer is reduced when switching costs are large. Therefore to avoid being replaced, the incumbent agrees to supply the buyer at lower prices. In effect, the buyer can commit to punishing the incumbent in the future for failing to reduce price now, provided switching costs are sufficiently large. ${ }^{4}$

Our analysis also predicts that integrated procurers (organizations that obtain supplies internally) and outsourcing procurers (organizations that buy supplies from outside producers) will manage switching costs differently in several respects. Whereas integrated procurers switch suppliers efficiently, since all their switching costs are internalized within the organization, outsourcer switching decisions are inefficient in various respects. We demonstrate outsourcers are likely to switch suppliers more often than is efficient. Outsourcers will invest too much in acquiring skills, but too little in retaining skill. Outsourcers will discourage standardization and compatibility of inputs, and will select an inflexible technology difficult to adapt for using different inputs. All of these inefficiencies are responses of the outsourcer to extort better terms of trade from their input suppliers.

In what follows we first present two related examples to motivate and illustrate our analysis in Section 2. In Section 3, we introduce a model of procurement and demonstrate that an equilibrium to the procurement game for both the integrated and outsourcing procurer exists. There we also contrast our analysis with earlier related studies of procurement and switching costs. Section 4 compares how the integrated procurer and outsourcer respond to switching costs through their choice of technology and organization structure. In Section 5, we analyze the benefits of faster skill acquisition and retention for the integrated and outsourcing procurer. Section 6 compares the behavior and preferences of the integrated buyer and outsourcer when suppliers' inputs possess different degrees of compatibility. Section 7 concludes with a summary of findings and suggestions for further work.

\section{EXAMPLES 5}

A buyer purchases exactly one unit of a product each period from one of two competing suppliers. The buyer and sellers are unable to commit to any long-term agreements, so each period the procurer arranges for the purchase of the product by making a take-it-or-leave-it price offer to each seller.

The private costs of supply for each producer are independently distributed over time and across suppliers. With probability equal to $1 / 2$ costs are either low $\left(c_{L}\right)$

\footnotetext{
${ }^{4}$ See Cabral and Villas-Boas (2004) for an interesting discussion of how other forms of competition among multiproduct (or multiperiod) competitors may affect producer profits and consumer welfare.

${ }^{5}$ We thank Paul Klemperer and Nicola Persico for assistance in constructing these examples.
} 
or they are high $\left(c_{H}\right)$ for supplier $i=1,2$ in each period. Although the products are perfect substitutes, each requires the buyer to learn a different set of skills to use the product most effectively. Whenever the buyer switches to a product he is unskilled at using, he incurs an adjustment cost in the form of a loss of surplus equal to $\Delta \geq 0$, for one period until he learns how to utilize the product. On the other hand, the buyer incurs no cost of switching if he recalls how to use the product from previous use. There is a likelihood $l \in[0,1]$ the buyer will lose his skill with a product he is not currently using. All parties discount future costs and benefits by $\delta \in[0,1)$.

2.1. Example with No Switching Cost and Private Supply Costs. For this example we assume $\Delta=0$ so a buyer never loses his skill at using a product. Further assume the supply cost for each producer is private knowledge. In this case, without the benefit of long-term contracts, the best the buyer can do is to conduct an auction each period to allocate supply to the lowest cost producer. ${ }^{6} \mathrm{~A}$ second price auction will accomplish this, and the expected acquisition price to the buyer each period will be $\frac{c_{L}+3 c_{H}}{4}$. Each supplier will earn an expected rent of $\frac{c_{H}-c_{L}}{4}$ each period due to their private information about cost. Without the ability to commit to long-term purchase agreements, there is little the procurer can do to reduce supplier rents. Threatening not to deal with a supplier in the future unless he discounts his current price is not credible for the buyer. When the future arrives, the buyer will obviously purchase from the supplier willing to produce at lowest price. The buyer will pay out a present value sum denoted by $C(\Delta=0)=\frac{c_{L}+3 c_{H}}{4(1-\delta)}$ for his lifetime product purchases.

2.2. Example with Switching Costs and Private Supply Costs. In our second example, we assume $\Delta>0$ so that there is a strictly positive one period switching cost incurred when the buyer tries a new product. At any point in time the buyer is always skilled at using the incumbent supplier's product, whereas he is unskilled at using the product of the other supplier, who can be thought of as a potential entrant.

Assume $\Delta<\left(c_{H}-c_{L}\right){ }^{7}$ This insures that the procurer will find it desirable to switch from the incumbent to the entrant sometimes. It is optimal for the buyer to switch when the entrant's $\operatorname{cost}$ is $c_{L}$ and the incumbent's cost is $c_{H}$ as the supply cost savings $\left(c_{H}-c_{L}\right)$ exceeds the cost of switching, $\Delta$. To implement this allocation the buyer specifies two prices, where $p^{I}$ is the price the buyer offers the incumbent for his product and $p^{E}$ is the price the buyer offers the entrant. The buyer asks each producer to report their supply costs in the current period. (Recall current period costs are privately observed by each supplier.) The buyer purchases from

\footnotetext{
${ }^{6}$ If the procurer could commit to a long-term agreement he could tax away all but the first-period rent by requiring the two suppliers to pay him a franchise entry fee equal to their expected future profit from a series of second price auctions the buyer would conduct to determine the supplier in each future period.

${ }^{7}$ When $\Delta \geq c_{H}-c_{L}$ the analysis is virtually unchanged, except that the procurer always buys from the incumbent.
} 
the entrant at price $p^{E}$ whenever he reports a supply cost that is strictly less than the incumbent's cost. Otherwise he purchases from the incumbent at price $p^{I}$.

Let $S^{I}$ and $S^{E}$ represent the expected present value of profits the incumbent and entrant producer expect to earn, respectively, given their current status under this pricing scheme. It is clear that $S^{E}=0$. This is because if the buyer ever purchases from the entrant (which occurs only when the entrant's cost is $c_{L}$ ), he will offer him the smallest price such that the entrant is indifferent between not producing and remaining the entrant or producing and becoming the incumbent supplier. In either case the entrant's expected profits are driven to zero by the procurer's offer price $p^{E}$, which satisfies $p^{E}-c_{L}+\delta S^{I}=\delta S^{E}=0$.

To calculate $S^{I}$ note the buyer's optimal strategy is similarly to offer the incumbent a price $p^{I}$ just sufficient to induce her to supply when her cost is high at $c_{H}$. That is, $p^{I}-c_{H}+\delta S^{I}=\delta S^{E}=0$ so that the incumbent is indifferent between supplying the product and remaining the incumbent and refusing to supply the product and becoming the entrant supplier with a future expected surplus of zero. The incumbent earns a profit only when her supply costs are low. Therefore, her expected surplus is given by $S^{I}=\frac{1}{2}\left(p^{I}-c_{L}+\delta S^{I}\right)$ or $S^{I}=\frac{c_{H}-c_{L}}{2}$ after substituting for $p^{I}=c_{H}-\delta S^{I}$. $^{8}$

Given that total producer profits $S^{I}+S^{E}=\frac{c_{H}-c_{L}}{2}$, the buyer's total expected acquisition cost over all periods for this case is $C(\Delta>0)=\frac{c_{H}-c_{L}}{2}+\frac{3 c_{L}+c_{H}}{4(1-\delta)}+$ $\frac{\Delta}{4(1-\delta)}$, where the second term represents the present value of minimum expected supply cost over time and the third term is the expected present value of switching costs over time. (Note switching occurs one fourth of the time when the incumbent's supply costs strictly exceeds the entrant's.)

Comparing the first two examples reveals that switching costs have a very different effect on consumers and on supplier pricing when buyers are strategic. The most important effect is the beneficial impact switching costs have on buyer's welfare with repeat purchasing. This is manifested in the lower acquisition costs of procurers in the presence of switching costs (provided the discount factor is not too small),

$$
C(\Delta=0)-C(\Delta>0)=\frac{2 \delta\left(c_{H}-c_{L}\right)-\Delta}{4(1-\delta)}>0 \text { for } \delta \in\left(\frac{1}{2}, 1\right) .
$$

Switching costs enable the procurer to commit to punishing suppliers who refuse to sell at low prices. Producers refusing to discount prices are replaced by rival suppliers, and once a seller is replaced he is less likely to be selected again to supply

\footnotetext{
${ }^{8}$ This pricing scheme is both incentive compatible and individually rational for both the incumbent and entrant. For instance, when the entrant's cost is $c_{H}$ he earns zero from truthfully reporting costs and $-\frac{1}{2}\left(c_{H}-c_{L}\right)$ from reporting costs equal to $c_{L}$. When his costs are $c_{L}$, he earns zero independent of his report. For the incumbent, he earns zero independent of his report when his $\operatorname{costs}$ are $c_{H}$. When costs are $c_{L}$ he earns $\left(c_{H}-c_{L}\right)$ from truthful reporting and only $\frac{1}{2}\left(c_{H}-c_{L}\right)$ from reporting higher costs.

Since each supplier earns nonnegative surplus in all states of the world, this pricing arrangement is also individually rational for each producer.
} 
as the procurer must incur a cost to switch suppliers. Moreover as the example illustrates for some markets, miniscule switching costs are sufficient to endow the procurer with all the commitment power he requires.

The switching cost example also illustrates different pricing dynamics from the bargain-rip off price path predicted in markets with passive buyers. In the example, equilibrium prices are stationary even when there is a switch in producers. Both incumbent and entrant are forced to maintain low prices-in the case of the entrant to penetrate the market, and in the case of the incumbent in order to maintain his preferred status with the buyer. Although the strict stationarity of price is peculiar to this example, price variation is nonetheless quite small in the more general settings we consider below.

To conclude our example, we note that the advantage of switching cost diminishes with the number of suppliers and may even become injurious to the buyer as the number of suppliers increases. To illustrate, suppose there are $n \geq 2$ independent suppliers, each drawing a cost of $c_{j}$ for $j=L, H$ with probability $1 / 2$ each period. When switching costs are zero the buyer's best strategy is to conduct a second-price supply auction each period. For this case the buyer's expected long-run procurement cost is $C^{n}(\Delta=0)=\frac{c_{L}\left(1-\left(\frac{1}{2}\right)^{n}\right)+c_{H}\left(\frac{1}{2}\right)^{n}}{1-\delta}+\frac{c_{H}-c_{L}}{1-\delta} n\left(\frac{1}{2}\right)^{n}$, where the first term is the expected cost of supply and the second term is the expected information rent accruing to suppliers. ${ }^{9}$

For the buyer with strictly positive switching cost, his optimal strategy is to purchase from the incumbent producer at a price of $p^{I}=c_{H}-\delta S^{I}$, unless an entrant supplier reports a strictly smaller cost of production. As in the case of two suppliers, the incumbent only earns a rent when his $\operatorname{cost}$ is $c_{L}$, which occurs with probability $1 / 2$. Thus, the incumbent's expected surplus is $S^{I}=\frac{c_{H}-c_{L}}{2}$. For this case the buyer's total expected acquisition cost is $C^{n}(\Delta>0)=\frac{c_{L}\left(1-\left(\frac{1}{2}\right)^{n}\right)+c_{H}\left(\frac{1}{2}\right)^{n}}{1-\delta}+$ $\frac{c_{H}-c_{L}}{2}+\frac{\Delta \frac{1}{2}\left(1-\left(\frac{1}{2}\right)^{n-1}\right)}{1-\delta}$, where the first term is the expected production cost, the second term is the expected rent the incumbent earns, and the third term represents the expected switching cost. ${ }^{10}$

Note that the difference in long-run expected acquisition cost with and without switching costs is $C^{n}(\Delta=0)-C^{n}(\Delta>0)=\frac{c_{H}-c_{L}}{1-\delta}\left(\frac{1}{2}\right)^{n} n-\frac{c_{H}-c_{L}}{2}-\frac{\Delta \frac{1}{2}\left(1-\left(\frac{1}{2}\right)^{n-1}\right)}{1-\delta}$, which tends toward $-\frac{c_{H}-c_{L}}{2}-\frac{\Delta}{2(1-\delta)}<0$ as $n$ grows sufficiently large. When the number of suppliers grows sufficiently large, acquisition costs increase with switching costs. This occurs because at least one supplier will have production costs of $c_{L}$ as each period approaches 1 . Consequently supplier rents vanish. The buyer no longer requires switching costs to induce sellers to lower their supply price. In this case as well as settings in which the buyer can observe suppliers' costs, switching costs serve only to increase the acquisition costs of the buyer.

Clearly these examples are special in some respects and this is the cause for some of the very sharp and dramatic effects of switching costs we observe. For

\footnotetext{
${ }^{9}$ A supplier is able to earn a rent of $\left(c_{H}-c_{L}\right)$ when he is the only one drawing a low cost, $c_{L}$. This occurs with probability $\left(\frac{1}{2}\right)^{n}$. Since there are $n$ suppliers the total expected rent each period is $\left(c_{H}-c_{L}\right) n\left(\frac{1}{2}\right)^{n}$.

${ }^{10}$ A switching cost is incurred when the incumbent's cost is $c_{H}$, which occurs with probability $1 / 2$, and at least one entrant has a cost of $c_{L}$, which occurs with probability $\left(1-\left(\frac{1}{2}\right)^{n-1}\right)$.
} 
example, the two-point distribution for supply costs in the example means that even the slightest amount of switching costs endows the procurer with significant ability to control supply prices. The stationarity of prices is also due to the twopoint cost distribution and the most rapid learning and forgetting of skills we assume. Nonetheless, the central predictions from the examples that (1) switching costs benefit buyers by enabling them to better control supply prices, and (2) the moderation of the wide swings between promotion and rip-off prices with strategic buyers continue to hold in the more general setting that follows.

\section{THE MODEL}

Our model builds on and extends previous analysis by Lewis and Yildirim (2002). We begin with the outsourcing procurer. The outsourcer must purchase materials each period from one of two independent suppliers $i=1,2$. Each supplier $i$ incurs privately known $\operatorname{costs} c_{i}$. These costs vary in an interval $[0, \bar{c}]$ and are assumed to be independently and identically distributed (i.i.d.) over time and across producers. For convenience, we assume $c_{i}$ is uniformly distributed by $F\left(c_{i}\right)=\frac{c_{i}}{\bar{c}}$. We denote the vector of supply costs by $\mathbf{c} \equiv\left(c_{1}, c_{2}\right)$.

The buyer derives value $v\left(x_{i}\right)$ from consuming good $x_{i} \in\{s, u\}$. For $x_{i}=s(u)$ the buyer is skilled (unskilled) at employing the product. The buyer derives greater value when he is skilled so that $v(s)-v(u)=\Delta>0$. The differential $\Delta$ measures the additional surplus the procurer receives when he is able to effectively use an input, perhaps a machine or piece of equipment, a type of computer software, or an information processing procedure he requires for his business.

To utilize the product effectively may require training employees, coordination of activities throughout the firm, or the acquisition of other complementary products or service used in conjunction with the input. There is considerable documentation of the importance of learning by doing as a way firms acquire skill in using products and processes. At the same time there is growing evidence that firms may also lose or forget skills when products or procedures are not used for some period of time. The process of acquiring and losing skill depending on the intensity of product use appears to be a significant source of switching cost in various manufacturing, electronic, computer equipment and software, energy, and service sector markets. ${ }^{11}$ Following this it seems reasonable to model the acquisition of skill as a stochastic learning by doing and forgetting the Markov type of process that satisfies

Assumption 1. For $i, j=1,2$ and $i \neq j$,

$$
\begin{array}{llll}
\Phi_{u, s}^{i}(i)=a & \Phi_{u, u}^{i}(i)=1-a & \Phi_{s, s}^{i}(j)=1-l & \Phi_{u, s}^{i}(j)=0 \\
\Phi_{s, s}^{i}(i)=1 & \Phi_{s, u}^{i}(i)=0 & \Phi_{s, u}^{i}(j)=l & \Phi_{u, u}^{i}(j)=1
\end{array}
$$

${ }^{11}$ See, for instance, Alchian (1963), Asher (1956), and Wright (1936) in aircraft production; Hirsch (1952) in machine tools; Dudley (1972) in metal products; Gruber (1998) and Nye (1996) in semiconductors; Joskow and Rozanski (1979) and Zimmerman (1982) in nuclear power. Argote et al. (1990), Benkard (2000), and Darr et al. (1995) document the importance of forgetting or depreciation of knowledge in manufacturing, industrial, and service sector industries. 
If the buyer selects an unskilled product $i$ to use, $\Phi_{u, s}^{i}(i)=a \in[0,1]$ is the probability the buyer will acquire skill using the product in that period, and $\Phi_{u, u}^{i}(i)=$ $1-a$ is the probability the product will remain unskilled. The buyer retains his skill with an input (or we will say an input remains skilled), provided the buyer continues to use it, so $\Phi_{s, s}^{i}(i)=1$. When the buyer is not employing a skilled input $i$, there is a probability $\Phi_{s, u}^{i}(j)=l \in[0,1]$ he will lose his skill by forgetting or by losing complementary services that enhance the use of the input. An input remains unskilled while it is not being utilized, so that $\Phi_{u, u}^{i}(j)=1$. The special case in which $\Phi_{u, s}^{i}(i)=1$ and $\Phi_{s, u}^{i}(j)=0$ so that learning always occurs and skill is permanently retained even when the input is not utilized is analyzed in Lewis and Yildirim (2002). ${ }^{12}$ In that case switching costs vanish eventually as either the buyer becomes skilled using both inputs or she specializes in employing only the skilled input, so that she never incurs costs of switching. The current analysis extends this to settings in which skill acquisition and forgetting are uncertain so that the buyer may incur a positive cost whenever she switches from a skilled to unskilled input.

There are four possible skill states $\left\{\mathbf{U}, \mathbf{M}_{1}, \mathbf{M}_{2}, \mathbf{S}\right\}$ with $\mathbf{U}=(u, u), \mathbf{M}_{1}=(s, u)$, $\mathbf{M}_{2}=(u, s), \mathbf{S}=(s, s)$. The skill state $\mathbf{x}=\left(x_{1}, x_{2}\right)$, and the acquisition and loss probabilities $a$ and $l$ are public knowledge. Given $\mathbf{x}, a$, and $l$, the $4 \times 4$ Markov transition matrix $P_{\mathbf{U}, \mathbf{M}_{1}, \mathbf{M}_{2}, \mathbf{S}}^{1}$ with $\left(\mathbf{x}, \mathbf{x}^{\prime}\right)$ element $\rho_{\mathbf{x} \mathbf{x}^{\prime}}(1)=\operatorname{Pr}\left(\mathbf{x}^{\prime} \mid \mathbf{x}\right)$ equal to the probability of moving from state $\mathbf{x}$ to state $\mathbf{x}^{\prime}$ upon using product 1 is

$$
P_{\mathbf{U}, \mathbf{M}_{1}, \mathbf{M}_{2}, \mathbf{S}}^{1}=\left(\begin{array}{cccc}
1-a & a & 0 & 0 \\
0 & 1 & 0 & 0 \\
l(1-a) & l a & (1-l)(1-a) & (1-l) a \\
0 & l & 0 & 1-l
\end{array}\right)
$$

(The symmetry of suppliers implies the transition matrix $P_{\mathbf{U}, \mathbf{M}_{1}, \mathbf{M}_{2}, \mathbf{S}}^{2}$ when seller 2 supplies are obtained from $P_{\mathbf{U}, \mathbf{M}_{1}, \mathbf{M}_{2}, \mathbf{S}}^{1}$ by switching row $\mathbf{M}_{2}$ for $\mathbf{M}_{1}$.)

3.0.1. Procurement process. A convenient way of modeling the outsourcer's acquisition of products is to assume he holds an optimal auction each period. The timing and information structure for the series of repeated auctions is

(i) Each period, before meeting, seller $i$ privately observes $\operatorname{cost} c_{i}$. The current skill state $\mathbf{x}$ is publicly observed.

(ii) The procurer offers a trading mechanism for that period, consisting of a $\left\{\lambda_{i}^{o}(\mathbf{x}, \mathbf{c}), P_{i}^{o}(\mathbf{x}, \mathbf{c})\right\}^{13}$ pair for each seller $i=1,2$ indicating the probability $\lambda_{i}^{o}(\mathbf{x}, \mathbf{c}) \in[0,1]$ of awarding production to seller $i$ and the payment seller

\footnotetext{
${ }^{12}$ In Lewis and Yildirim (2002) suppliers' expected cost of supply falls with previous cumulative production, as a result of learning by doing. The model allows for an arbitrary finite number of cost (skill) levels. However, unlike the current analysis, the possibility of losing skill through inactivity is ruled out.

${ }^{13}$ Variables with an "o" superscript correspond to the outsourcer.
} 
$i$ receives. We require $\lambda_{1}^{o}(\mathbf{x}, \mathbf{c})+\lambda_{2}^{o}(\mathbf{x}, \mathbf{c})=1$; the buyer purchases exactly one unit of input. ${ }^{14}$

(iii) Given the schedule $\left\{\lambda_{i}^{o}(\mathbf{x}, \mathbf{c}), P_{i}^{o}(\mathbf{x}, \mathbf{c})\right\}$ each supplier decides whether to participate in the current auction. (All sellers agree to participate in equilibrium.)

(iv) Finally, suppliers simultaneously and confidentially report their costs $c_{i}$. The buyer pays the suppliers and picks one to produce. After production, the skill state, $\mathbf{x}$, is updated by the Markov transition probabilities $\rho_{\mathbf{x x}^{\prime}}(i)$, whereupon the next procurement commences.

Before characterizing equilibrium let us note some important features of our analysis and how it compares to earlier studies. Our analysis builds on and extends an early paper by Lewis and Yildirim (2002), who examine how a large buyer controls dynamic competition among rival suppliers to exploit learning by doing economies. Cabral and Riordan (1994) also analyze the effect of learning economies on industry competition, but for the case in which buyers are price takers. In these analyses, suppliers acquire skill at producing goods for the buyer the more often they produce. Acquired skill is retained even during periods of slack production. This implies that a buyer who has purchased from a particular supplier previously may continue buying from that producer, possibly to the exclusion of other suppliers. These analyses focus on identifying what factors will cause the market to tip entirely to one supplier and how the procurer selects suppliers to exploit learning economies while reducing the costs of becoming locked in to one producer.

An important limitation of Lewis and Yildirim (2002) is that there are no costs to switching producers in the long run, as either all suppliers eventually become equally skilled at production or the buyer ends up purchasing exclusively from a single most efficient supplier. The current analysis extends Lewis and Yildirim by assuming learning is stochastic and that skill may be lost through inactivity. The analysis to follow compares and contrasts policies designed to manage lock-in in the case of Lewis and Yildirim (2002) and switching costs in the case of the current analysis.

Cabral and Greenstein (1990) also focus on ways that large procurers can deal with switching costs. They investigate whether procurers should commit to ignore switching costs in selecting suppliers to induce more competitive pricing. In contrast our analysis assumes that such commitment is not possible or credible and that the buyer is unable to commit to a long-term procurement policy due to well-known political and legal constraints. ${ }^{15}$ Nonetheless, the buyer may influence future procurements by varying switching costs through his choice of technology, firm organization, and choice of suppliers. This feature enables us to compare the

\footnotetext{
${ }^{14} \mathrm{We}$ assume the buyer is able to use just one input each period. We are abstracting from the possibility of second sourcing as in Anton and Yao (1987).

${ }^{15}$ It is notoriously difficult for government buyers to commit to long-term procurements. Administrative rules prohibit public officials from committing future elected or appointed officials to a long-term policy of procurement. Regarding private procurements, incompleteness of contracts and enforcement problems make it unlikely a buyer and seller can commit themselves to a long-term supply agreement.
} 
role of switching costs among different procurer types including integrated buyers and outsourcers. Importantly for our purposes it also permits a comparison of the effects of switching costs where buyers are either small price-taking agents or large purchasers with market power. Specifically, we examine how optimal auctions that account for switching costs are implemented by the buyer to induce price concessions from the incumbent supplier to avoid being replaced. In this regard our model utilizes recent theories of Jehiel et al. (1996, 1999) and Segal (1999) on competition design with externalities to characterize the optimal procurement auction.

Assuming suppliers' costs, $c_{i}$ 's, are i.i.d over time and across suppliers rules out strategic learning about suppliers' costs from their current behavior. Also we assume suppliers observe the buyer's ability to utilize their inputs. ${ }^{16}$ Thus, our model abstracts from possibly interesting issues of strategic learning and signaling. ${ }^{17} \mathrm{We}$ do this deliberately to focus on the role of switching costs in the optimal design of procurement.

Finally, we model the interaction between the buyer and two suppliers as an infinite horizon Markov game. The parties condition their strategies on the payoff relevant state of the game they individually observe each period. Below we characterize the Markov Perfect Equilibrium (MPE) for this game. ${ }^{18}$ The focus on Markovian behavior has intuitive appeal here where we study how the procurer's skill state affects purchases each period.

3.1. Outsourcing Procurement: Characterization of Equilibrium. Let $B^{o}(\mathbf{x})$, $S u_{1}^{o}(\mathbf{x})$, and $S u_{2}^{o}(\mathbf{x})$ be the expected discounted present value for the buyer and for suppliers 1 and 2, respectively, from participating in current and future procurements given the current state, $\mathbf{x}$. In our proof of existence and uniqueness of anonymous MPE in Proposition 1 below, we show that these value functions exist and are well defined. All parties discount future returns and costs by the same discount factor $\delta \in[0,1)$.

Each period the buyer offers a menu $\left\{\lambda_{i}^{o}(\mathbf{x}, \mathbf{c}), P_{i}^{o}(\mathbf{x}, \mathbf{c})\right\}$ for sellers $i=1,2$ to select from. Given this menu seller $i$ 's value function is $S u_{i}^{o}(\mathbf{x}):=E_{c_{i}} S u_{i}^{o}\left(\mathbf{x}, c_{i}\right)$, where

$$
\begin{aligned}
S u_{i}^{o}\left(\mathbf{x}, c_{i}\right)=\max _{\hat{c}_{i}}\{ & P_{i}^{o}\left(\mathbf{x}, \hat{c}_{i}\right)-\lambda_{i}^{o}\left(\mathbf{x}, \hat{c}_{i}\right) c_{i} \\
& \left.+\delta\left[\lambda_{i}^{o}\left(\mathbf{x}, \hat{c}_{i}\right) \sum_{\mathbf{x}^{\prime}} \rho_{\mathbf{x x}^{\prime}}(i) S u_{i}^{o}\left(\mathbf{x}^{\prime}\right)+\lambda_{j}^{o}\left(\mathbf{x}, \hat{c}_{i}\right) \sum_{\mathbf{x}^{\prime}} \rho_{\mathbf{x} \mathbf{x}^{\prime}}(j) S u_{i}^{o}\left(\mathbf{x}^{\prime}\right)\right]\right\}
\end{aligned}
$$

\footnotetext{
16 That suppliers observe the buyer's skill with their input seems reasonable for the settings we have in mind. Appleyard (2002) indicates suppliers often work with buyers to assist in the use of their product. Also, the buyer will often reveal his state of skill and knowledge in operating products in the course of specifying material requirements for procurement.

17 The effects of strategic learning in optimal procurement are surveyed in Laffont and Tirole (1993). Other analyses of strategic learning in multiperiod settings include the interesting papers by Bergemann and Valimaki (1996), Burguet (1996), Keller and Rady (1999), Kennan (2001), Rustichini and Wolinski (1995), and Taylor (2002).

${ }^{18}$ See Maskin and Tirole (2001) for a rigorous characterization and comprehensive discussion of the properties of Markov equilibirium.
} 
and $P_{i}^{o}\left(\mathbf{x}, c_{i}\right) \equiv E_{c_{j}}\left[P_{i}^{o}(\mathbf{x}, \mathbf{c})\right]$, and $\lambda_{i}^{o}\left(\mathbf{x}, c_{i}\right) \equiv E_{c_{j}}\left[\lambda_{i}^{o}(\mathbf{x}, \mathbf{c})\right]$ with $E_{c}$ being the expectation operator with respect to $c$.

Equation (IC) indicates that upon observing $\left(\mathbf{x}, c_{i}\right)$ supplier $i$ reports his cost to the buyer to maximize the discounted expected value $S u_{i}^{o}\left(\mathbf{x}, c_{i}\right)$. This expected value consists of current returns $P_{i}^{o}\left(\mathbf{x}, \hat{c}_{i}\right)-\lambda_{i}^{o}\left(\mathbf{x}, \hat{c}_{i}\right) c_{i}$ plus seller $i$ 's future expected continuation value. This continuation value is the sum of the probabilities that the skill state will transition from states $\mathbf{x}$ to states $\mathbf{x}^{\prime}, \rho_{\mathbf{x x}^{\prime}}(i)$, multiplied by seller $i$ 's expected surplus in each state, $S u_{i}^{o}\left(\mathbf{x}^{\prime}\right)$, multiplied by the probability that each supplier $i$ and $j$ is selected by the procurer.

To implement a particular assignment of production requires the menu $\left\{\lambda_{i}^{o}(\mathbf{x}, \mathbf{c}), P_{i}^{o}(\mathbf{x}, \mathbf{c})\right\}$ offered satisfy incentive compatibility (IC) or truthful reporting of costs by each seller. To insure participation, the contract must yield supplier $i$ expected discounted net returns at least equal to its expected return from rejecting the current contract. In the terminology of Jehiel et al. $(1996,1999)$ our auction is one with externalities. The identity of the winning bidder affects the welfare of other bidders and the buyer. ${ }^{19}$ Here if seller $i$ refuses to participate, the buyer optimally responds by purchasing the input from $i$ 's rival, seller $j$. Consequently participation requires for $i=1,2$

$$
S u_{i}^{o}\left(\mathbf{x}, c_{i}\right) \geq \delta \sum_{\mathbf{x}^{\prime}} \rho_{\mathbf{x x}^{\prime}}(j) S u_{i}^{o}\left(\mathbf{x}^{\prime}\right)
$$

Each seller at least receives her surplus from not currently participating in the market. Note further we are assuming that sellers remain in the market provided they expect to at least break even in future periods. ${ }^{20}$

Combining the requirements for (IC) and (IR), we obtain the following characterization of implementable allocations.

LEMMA 1. For any procurement allocation satisfying (IC) and (IR), the expected payment and surplus for seller $i$ are given respectively by

$$
\begin{gathered}
P_{i}^{o}\left(\mathbf{x}, c_{i}\right)=\lambda_{i}^{o}\left(\mathbf{x}, c_{i}\right) c_{i}+\int_{c_{i}}^{\bar{c}} \lambda_{i}^{o}\left(\mathbf{x}, \tilde{c}_{i}\right) d \tilde{c}_{i}-\delta \lambda_{i}^{o}\left(\mathbf{x}, c_{i}\right) \sum_{\mathbf{x}^{\prime}}\left[\rho_{\mathbf{x} \mathbf{x}^{\prime}}(i)-\rho_{\mathbf{x x}^{\prime}}(j)\right] S u_{i}^{o}\left(\mathbf{x}^{\prime}\right) \\
(2) \quad S u_{i}^{o}(\mathbf{x})=\delta \sum_{\mathbf{x}^{\prime}} \rho_{\mathbf{x} \mathbf{x}^{\prime}}(j) S u_{i}^{o}\left(\mathbf{x}^{\prime}\right)+E_{c_{i}}\left[\lambda_{i}^{o}\left(\mathbf{x}, c_{i}\right) c_{i}\right]
\end{gathered}
$$

\footnotetext{
${ }^{19}$ See Jehiel et al. (1996, 1999) for an analysis of optimal auctions and Das Varma (2002) for an analysis of standard auctions with externalities.

${ }^{20}$ To insure each seller participates, the buyer makes the following offer. If a seller $i$ refuses to participate, the buyer offers to pay seller $j$ a sufficiently high price to induce her to supply the input. Therefore it never strictly benefits seller $i$ to refuse participation, provided (IR) is satisfied. Further it is not an equilibrium for both sellers to refuse to participate, since one of the sellers would find it optimal to deviate and agree to participate given the buyer's offer. Therefore, both sellers will participate in equilibrium.

The possibility that sellers could conspire by arranging for the entrant producer to stay out of the market for some period is discussed briefly in Section 7.
} 
Proof. All proofs are contained in the Appendix.

The buyer offers the sellers a menu $\left\{\lambda_{i}^{o}(\mathbf{x}, \mathbf{c}), P_{i}^{o}(\mathbf{x}, \mathbf{c})\right\}$ satisfying (IR) and (IC) to maximize expected surplus, $B^{o}(x)$, defined recursively by

$$
\begin{aligned}
B^{o}(\mathbf{x})=E_{c}\{ & \lambda_{1}^{o}(\mathbf{x}, \mathbf{c}) v\left(x_{1}\right)+\lambda_{2}^{o}(\mathbf{x}, \mathbf{c}) v\left(x_{2}\right)-\left[P_{1}^{o}(\mathbf{x}, \mathbf{c})+P_{2}^{o}(\mathbf{x}, \mathbf{c})\right] \\
& \left.+\delta \sum_{\mathbf{x}^{\prime}} B^{o}\left(\mathbf{x}^{\prime}\right)\left[\lambda_{1}^{o}(\mathbf{x}, \mathbf{c}) \rho_{\mathbf{x x}^{\prime}}(1)+\lambda_{2}^{o}(\mathbf{x}, \mathbf{c}) \rho_{\mathbf{x} \mathbf{x}^{\prime}}(2)\right]\right\}
\end{aligned}
$$

Substituting the Lemma 1 expression for $P_{i}^{o}(\mathbf{x}, \mathbf{c})$ into (3) we obtain the buyer's problem

$$
\begin{aligned}
B^{o}(\mathbf{x}) & =\max _{\left\{\lambda_{i}(\mathbf{x}, \mathbf{c})\right\}} E_{c}\left\{\sum_{i=1,2}\left[\lambda_{i}^{o}\left(\mathbf{x}, c_{i}\right) z_{i}^{o}\left(\mathbf{x}, c_{i}\right)-\delta \sum_{\mathbf{x}^{\prime}} \rho_{\mathbf{x} \mathbf{x}^{\prime}}(j \neq i) S u_{i}^{o}\left(\mathbf{x}^{\prime}\right)\right]\right\} \\
& =E_{c}\left\{\max \left[z_{1}^{o}\left(\mathbf{x}, c_{1}\right), z_{2}^{o}\left(\mathbf{x}, c_{2}\right)\right]-\delta \sum_{i=1,2} \sum_{\mathbf{x}^{\prime}} \rho_{\mathbf{x x}^{\prime}}(j \neq i) S u_{i}^{o}\left(\mathbf{x}^{\prime}\right)\right]
\end{aligned}
$$

where $z_{i}^{o}\left(\mathbf{x}, c_{i}\right) \equiv v\left(x_{i}\right)+\delta \sum_{\mathbf{x}^{\prime}} \rho_{\mathbf{x x}^{\prime}}(i) W^{o}\left(\mathbf{x}^{\prime}\right)-2 c_{i}$ and $W^{o}(\mathbf{x}) \equiv B^{o}(\mathbf{x})+S u_{1}^{o}(\mathbf{x})+$ $S u_{2}^{o}(\mathbf{x})$ is total surplus. Equation (4) indicates the buyer selects the seller generating the greatest net surplus $z_{i}$ to the buyer. Net surplus consists of the current value of consumption, $v\left(x_{i}\right)$ plus the expected future discounted total surplus generated with supplier $i$, minus production cost, $c_{i}$, and seller $i$ 's information rent, $\frac{F\left(c_{i}\right)}{f\left(c_{i}\right)}=c_{i}$ for the uniform distribution. Since the buyer guarantees each seller her expected surplus from not participating, one subtracts this expected surplus, $\delta \sum_{i=1,2} \sum_{\mathbf{x}^{\prime}} \rho_{\mathbf{x x}^{\prime}}(j \neq i) S u_{i}^{o}\left(\mathbf{x}^{\prime}\right)$, from total surplus to obtain the buyer's expected surplus, $B^{o}(\mathbf{x})$.

It is convenient to interpret the buyer's optimal purchase decision in terms of switching costs. According to Equation (4) the buyer purchases input 1 if and only if $z_{1}^{o}\left(\mathbf{x}, c_{1}\right) \geq z_{2}^{o}\left(\mathbf{x}, c_{2}\right)$. This is equivalent to purchasing from supplier 1 if and only if

$$
2 c_{1} \leq s c^{o}(\mathbf{x})+2 c_{2}
$$

where

$$
s c^{o}(\mathbf{x}) \equiv v\left(x_{1}\right)-v\left(x_{2}\right)+\delta \sum_{\mathbf{x}^{\prime}} W^{o}\left(\mathbf{x}^{\prime}\right)\left[\rho_{\mathbf{x} \mathbf{x}^{\prime}}(1)-\rho_{\mathbf{x} x^{\prime}}(2)\right]
$$

is the cost of switching when the buyer is currently purchasing from seller 1 . Switching costs consists of $v\left(x_{1}\right)-v\left(x_{2}\right)$, the current advantage of using input 1 over input 2 , and the expected loss in total future surplus $\delta \sum_{\mathbf{x}^{\prime}} W^{o}\left(\mathbf{x}^{\prime}\right)\left[\rho_{\mathbf{x} x^{\prime}}(1)-\right.$ $\left.\rho_{\mathbf{x} x^{\prime}}(2)\right]$ from selecting seller 2 instead of 1 . According to Equation (5) supplier 1 is selected if and only if the total cost (including production cost plus information rents) of buying from supplier 1 is less than the full cost of buying from supplier 2 
including the cost of switching from supplier 1 to 2 . Note that we have defined switching costs in terms of the cost of switching from supplier 1 to supplier 2. Consequently the cost of switching from supplier 2 to supplier 1 is $-s c^{o}(\mathbf{x})$.

An MPE for the repeated procurement game described above is comprised of a set of best reply strategies for all players conditioned on $\mathbf{x}$ the skill state and on transitory costs in the case of suppliers. The buyer's strategy, $\left\{\lambda_{1}^{o}(\mathbf{x}, \mathbf{c}), \lambda_{2}^{o}(\mathbf{x}, \mathbf{c})\right\}$, maximizes her expected surplus in (4). Recall that in deriving (4), we have already required the truthful reporting of suppliers' costs and their participation strategies to be Bayesian best responses to each other. In addition these strategies are each a best response to the buyer's contract offers for all conceivable histories of the game, summarized by the evolution of the state variable $\mathbf{x}$. In what follows we restrict attention to anonymous MPE. In such equilibria the buyer 's procurement strategy depends only on the current skill state, where states $\{u, s\}$ and $\{s, u\}$ are equivalent. $^{21}$

In what follows we assume

Condition (A): $D \equiv \delta\left[\frac{a(1-l)}{1-\delta(1-l)}+\frac{l(1-a)}{1-\delta(1-a)}\right] \leq 16$.

Condition (A) is sufficient for uniqueness of symmetric MPE, and it is satisfied for $a, l \in[0,1]$ and $\delta \in\left[0, \frac{16}{17}\right]$. Summarizing our results to this stage we have ${ }^{22}$

Proposition 1. Given Condition (A), there exists a unique anonymous MPE for the procurement game satisfying (4), (IC), (IR), and (6) with the property in each state, $\mathbf{x}$ there exists a unique switching cost sc ${ }^{\circ}(\mathbf{x})$ that determines the allocation of supply such that producer 1 is selected provided $2 c_{1} \leq s c^{o}(x)+2 c_{2}$, otherwise producer 2 is chosen.

3.2. Integrated Procurement: Assumptions and Equilibrium Characterization. The integrated procurement setting differs from the outsourcing case only in that the sellers and buyers act cooperatively to maximize total surplus. Otherwise the assumptions governing the two settings are identical.

Let $B^{I}(x)$ denote the combined surplus of the integrated buyer-sellers, and denote by $\lambda_{i}^{I}\left(\mathbf{x}, c_{i}\right)$ the probability that supplier $i$ is chosen to produce in state, $\mathbf{x}$, where the superscript " $I$ " refers to the integrated buyer-supplier case. Note that buyer's surplus coincides with total surplus so $B^{I}(x)=W^{I}(x)$ in this case. Proceeding as above define buyer's surplus by

$$
\begin{aligned}
B^{I}(\mathbf{x}) & =\max _{\left\{\lambda_{i}(\mathbf{x}, \mathbf{c})\right\}} E_{c} \sum_{i=1,2}\left[\lambda_{i}^{I}(\mathbf{x}, \mathbf{c}) z_{i}^{I}(\mathbf{x}, \mathbf{c})\right] \\
& =E_{c} \max _{i \in\{1,2\}}\left\{z_{i}^{I}(\mathbf{x}, \mathbf{c})\right\}
\end{aligned}
$$

\footnotetext{
${ }^{21}$ We conjecture only anonymous MPEs exist, though we have been unable to prove this.

22 The limiting case where $a=1$ and $l=0$ is one in which there are no switching costs, other than the initial difference in skill between the incumbent and entrant good. The equilibrium characterized in Proposition 1 holds for the limiting case as well.
} 
where $z_{i}^{I}\left(\mathbf{x}, c_{i}\right) \equiv v\left(x_{i}\right)+\delta \sum_{\mathbf{x}^{\prime}} \rho_{\mathbf{x x}^{\prime}}(i) W^{I}\left(\mathbf{x}^{\prime}\right)-c_{i}$. There exists a unique solution for the integrated buyer-sellers case described in

Proposition 2. There exists a unique solution to (7) with the property in each state, $\mathbf{x}$ there exists a unique switching cost $s c^{I}(\mathbf{x}) \equiv v\left(x_{1}\right)-v\left(x_{2}\right)+$ $\delta \sum_{\mathbf{x}^{\prime}} W^{I}\left(\mathbf{x}^{\prime}\right)\left[\rho_{\mathbf{x x}^{\prime}}(1)-\rho_{\mathbf{x x}^{\prime}}(2)\right]$ that determines the allocation of supply such that producer 1 is selected provided $c_{1} \leq s c^{I}(\mathbf{x})+c_{2}$, otherwise producer 2 is chosen.

\section{COMPARING BUYER RESPONSES TO SWITCHING COSTS}

The qualitative response of integrated buyers and outsourcers to switching costs is the same in several respects as reported in the next proposition.

Proposition 3. Given the integrated buyer $(I)$, outsourcer $(O)$, and skill states $\left(\mathbf{U}, \mathbf{M}_{1}, \mathbf{M}_{2}, \mathbf{S}\right)$, in equilibrium for $k=I, O$

(a) $s c^{k}\left(\mathbf{M}_{1}\right)>s c^{k}(\mathbf{S})=0=s c^{k}(\mathbf{U})>s c^{k}\left(\mathbf{M}_{2}\right)$.

(b) $\frac{\partial s c^{k}\left(\mathbf{M}_{1}\right)}{\partial a} \leq 0, \frac{\partial s c^{k}\left(\mathbf{M}_{1}\right)}{\partial l} \geq 0$ (with strict inequality when $s c^{I}\left(\mathbf{M}_{1}\right) \in[0, \bar{c})$ ), or $s c^{o}\left(\mathbf{M}_{1}\right) \in[0,2 \bar{c})$.

(c) The likelihood of switching is decreasing with switching costs.

To interpret Proposition 3, recall the costs of switching from input 1 to 2, $s c^{k}(\mathbf{x}) \equiv v\left(x_{1}\right)-v\left(x_{2}\right)+\delta \sum_{\mathbf{x}^{\prime}} W\left(\mathbf{x}^{\prime}\right)\left[\rho_{\mathbf{x x}^{\prime}}(1)-\rho_{\mathbf{x x}^{\prime}}(2)\right]$, consists of a current cost $v\left(x_{1}\right)-v\left(x_{2}\right)$ and a long-run cost of switching, $\delta \sum_{\mathbf{x}^{\prime}} W\left(\mathbf{x}^{\prime}\right)\left[\rho_{\mathbf{x x}^{\prime}}(1)-\rho_{\mathbf{x x}^{\prime}}(2)\right]$. In the benchmark case typically assumed in the literature where $a=l=1$ skill acquisition and loss occur within one period of switching suppliers. There is a one-time cost equal to $\Delta$ when a switch occurs. More generally though, there is a future impact of a current supplier switch. For instance, when learning a skill is rapid and persistent so that $a=1, l<1$ part (b) of Proposition 3 implies $s c^{k}(\mathbf{x})<\Delta$. This reduction in switching costs reflects a diversification motive. By switching to the unskilled input, the buyer may eventually acquire skill with both inputs, thus permitting him to select whichever input is least costly to acquire in the future. Note however, that the future benefit to switching is never so great as to eliminate switching costs entirely. Part (a) implies there is always a positive cost to switching from a skilled to an unskilled input. In other instances, when skill learning is slow and immediately forgotten so that $a<1, l=1$, part (b) implies $s c^{k}(\mathbf{x})>\Delta$. This increase over the benchmark reflects a conservation motive for the buyer, whereby he is reluctant to switch for fear of losing his expertise with the skilled input. $^{23}$

${ }^{23}$ When $a=1$ and $l=0$ as in Lewis and Yildirim (2002), the diversification motive is pronounced. The buyer may continue purchasing from multiple suppliers, instead of tipping to one exclusively, if the variation in production costs is large relative to the cost reductions from experience. The incentive for the buyer to remain with the current supplier, due to the conservation motive, is not present in Lewis and Yildirim (2002). 
Part (c) of Proposition 3 shows procurers react to increasing switching costs by switching less often. Ex ante, buyers are more likely to purchase from the supplier of the skilled input. Otherwise the suppliers provide the input with equal probability when the buyer is equally skilled at employing their products. These predictions are consistent with evidence on vendor switching in Greenstein (1995). ${ }^{24}$

Part (b) reveals how switching costs decrease the easier it becomes to acquire skill and the less likely skill deteriorates from nonuse. Consequently, as part (c) indicates, switching from a skilled supplier is more likely the easier it is to acquire new skill and to retain old ones.

Although the integrated buyer and outsourcer responses to switching costs are qualitatively similar, they do differ quantitatively as indicated in the next proposition.

Proposition 4. The outsourcer incurs a smaller switching cost than the integrated buyer, and consequently switches from the skilled input more frequently than is efficient.

To understand Proposition 4, note that unlike the integrated buyer, the outsourcer is concerned with limiting the information rents of the producers. These rents become especially large in the state in which the outsourcer is not equally skilled in using the suppliers' products. Switching in that state is therefore less costly to the outsourcer than the integrated buyer. Since the integrated buyer behaves efficiently, this also implies that switching is excessive under outsourcing. ${ }^{25}$

This tendency toward excessive switching contrasts with other motives for switching that have been identified. For instance Taylor (2002) analyzes consumers with private costs to switching and finds that buyers may initially switch to signal they have low switching costs. This enables them to receive better terms of exchange in the future. Cabral and Greenstein (1990) find a buyer may commit to switching often by ignoring switching costs. This forces incumbent suppliers to price more competitively.

\section{COMPARING BENEFITS OF FASTER LEARNING AND SKILL RETENTION}

Generally one expects total surplus and buyer's surplus to increase when buyers acquire skill faster (greater $a$ ) and retain knowledge longer (smaller $l$ ). Although this always holds for the integrated buyer, surprisingly it does not for the outsourcer. To pave the way toward understanding these differences between integrated buyers and outsourcers we first characterize how surplus varies in different skill states.

\footnotetext{
${ }^{24}$ In his study of U.S. Government procurement of mainframe computers, Greenstein reports incumbents won $73 \%$ of the procurements.

${ }^{25}$ Lewis and Yildirim (2002) similarly show that the buyer switches from the more experienced supplier more often than is efficient. This reduces the rate of learning. Again this is done to reduce supplier rents.
} 
Proposition 5. In a procurement equilibrium,

(a) $B^{I}(\mathbf{S})>B^{I}\left(\mathbf{M}_{i}\right)>B^{I}(\mathbf{U})$

(b) $W^{o}(\mathbf{S})>W^{o}\left(\mathbf{M}_{i}\right)>W^{o}(\mathbf{U})$

(c) $B^{o}(\mathbf{S})>B^{o}\left(\mathbf{M}_{i}\right)>B^{o}(\mathbf{U})$

(d) $S u_{1}^{o}\left(\mathbf{M}_{1}\right)>\left(S u_{1}^{o}(\mathbf{S})\right.$ or $\left.S u_{2}^{o}(\mathbf{U})\right)>S u_{1}^{o}\left(\mathbf{M}_{2}\right)$

(e) $S u_{1}^{o}(\mathbf{S})+S u_{2}^{o}(\mathbf{S}) \gtreqless S u_{1}^{o}(\mathbf{U})+S u_{2}^{o}(\mathbf{U})$ as $a \gtreqless l$.

Parts (a)-(c) of Proposition 5 confirm that total surplus and buyer surplus are increasing in higher states of skill acquisition. In contrast we find in the outsourcing case, suppliers' surplus does not monotonically increase with skill in two respects. First, part (d) shows a supplier's surplus is increasing in the buyer's skill at operating his input, but that his surplus decreases when the buyer becomes skilled in employing the other input. Hence, each seller benefits from a skill differential. Suppliers may acquire this desired differential whenever the buyer employs their input. Likewise they may lose their differential if the buyer switches to another input. This produces a rivalry between suppliers to win the next procurement to acquire and maintain their skill differential.

A second respect in which supplier surplus is nonmonotonic is suppliers' total surplus may be smaller in the complete skilled state, $\mathbf{S}$, than it is in the complete unskilled case, $\mathbf{U}$, as indicated by part (e). This occurs when the skill loss rate is less than the learning rate. To understand why, note when suppliers are in state $\mathbf{U}$, they compete to win the current supply contract to gain a skill advantage over their rival. The likelihood of moving to the differential skill state, $\mathbf{M}_{i}$, conditional on winning is $a$, the learning rate. The higher $a$ the harder suppliers will compete to win procurement, knowing the winner is likely to gain a future advantage. Similarly, when suppliers are in state $\mathbf{S}$, they compete to win the next procurement to avoid skill loss. This occurs with probability $l$, conditional on losing the acquisition. The higher $l$, the harder suppliers compete to win to avoid a future loss of skill. Since suppliers' surplus is inversely related to the degree of rivalry between them, it will be greater in state $\mathbf{U}$ than in state $\mathbf{S}$ provided $a$ is less than $l .^{26}$

The rivalry between suppliers is manifested as a reduction in the price sellers offer to win the next procurement. From the expression for expected price in Equation (1) we see, conditional on winning, supplier $i$ 's price reduction, $R^{i}(\mathbf{x})=$ $\delta \sum_{\mathbf{x}^{\prime}}\left[\rho_{\mathbf{x x}^{\prime}}(i)-\rho_{\mathbf{x x}^{\prime}}(j)\right] S u_{i}^{o}\left(\mathbf{x}^{\prime}\right)$, is the present value decrease in $i$ 's future surplus if he loses the current procurement. This implies in multiperiod procurements, even the incumbent-skilled supplier must continue to price competitively to avoid losing his advantage. The "bargain followed by rip-off" pricing phenomenon emphasized in the switching cost literature moderates to a great degree when there are multiple procurements. Although part (d) of Proposition 5 implies $R^{j}\left(\mathbf{M}_{i}\right) \geq R^{i}\left(\mathbf{M}_{i}\right)$ so that unskilled suppliers offer deeper discounts than incumbent suppliers, the difference in discounts can be small. In fact the incumbent may price just as competitively

\footnotetext{
${ }^{26}$ Lewis and Yildirim (2002) predict that total supplier surplus is increasing as either supplier increases his skill. This is consistent with the prediction (e) of Proposition 5 for $a>l$. The interesting case in which supplier surplus decreases with the skill state is not predicted by Lewis and Yildirim (2002).
} 
as the unskilled supplier when, for instance, $a=l=1$, so the incumbent cedes his advantage to the other supplier after losing just one procurement. The intensity of pricing to maintain an incumbency advantage is particularly well illustrated by the example we analyzed in Section 2.

Armed with these results we are ready to understand how variations in the rate of learning, $a$, and the rate of skill loss, $l$, impact the integrated buyer and the outsourcer. In particular, we consider how the long-run steady-state surplus of the buyer is affected. For the integrated buyer, we define the long-run steadystate buyer's surplus $B^{I *}$ by

$$
B^{I *}(a, l)=\gamma_{\mathbf{U}} B^{I}(\mathbf{U})+\gamma_{\mathbf{M}_{1}} B^{I}\left(\mathbf{M}_{1}\right)+\gamma_{\mathbf{M}_{2}} B^{I}\left(\mathbf{M}_{2}\right)+\gamma_{\mathbf{S}} B^{I}(\mathbf{S})
$$

where $\gamma \equiv\left(\gamma_{\mathbf{U}}, \gamma_{\mathbf{M}_{1}}, \gamma_{\mathbf{M}_{2}}, \gamma_{\mathbf{S}}\right)$ is the vector of steady-state probabilities of occupying states $\left(\mathbf{U}, \mathbf{M}_{1}, \mathbf{M}_{2}, \mathbf{S}\right)$ defined by

$$
\left[\lambda_{1}(\mathbf{x}) \rho_{\mathbf{x}, \mathbf{x}^{\prime}}(1)+\lambda_{2}(\mathbf{x}) \rho_{\mathbf{x}, \mathbf{x}^{\prime}}(2)\right] \cdot \gamma^{\prime}=\gamma^{\prime}
$$

PRoposition 6. For the integrated buyer, steady-state buyer's surplus is increasing in the skill acquisition rate, a, and decreasing in the skill loss rate, l, as $\frac{\partial B^{I *}(a, l)}{\partial a}>0$ and $\frac{\partial B^{I *}(a, l)}{\partial l}<0$ whenever sc ${ }^{I}(a, l) \in[0, \bar{c}) .^{27}$

Given that switching costs significantly affect market performance, buyers have incentives to invest in procedures enabling them to manage switching costs most efficiently. This has implications for the integrated buyer's choice of technology and firm organization. Generally the integrated firm will benefit by adopting a flexible technology that utilizes a range of different types of inputs. For instance a power producer able to readily switch between burning natural gas or coal in its generator benefits by utilizing the currently lowest priced fuel. Manufacturing firms will benefit from installing flexible manufacturing systems (FMSs) that significantly reduce the setup costs of changing inputs and rearranging production runs. $^{28}$

The preferences of the outsourcer for learning and skill retention are summarized in the next three propositions. These propositions reference the following variables, $W^{o *}(a, l), B^{o *}(a, l)$, and $S u^{o *}(a, l)$, which are, respectively, the steadystate total surplus, buyer's surplus, and aggregate suppliers' surplus for the outsourcing case. ${ }^{29}$ The term $\Delta / \bar{c}=\frac{v(s)-v(u)}{\bar{c}}$ refers to the size of the skill cost differential relative to the variation in random production costs.

${ }^{27}$ When $s c^{I}(a, l)=\bar{c}$ variations in $a$ and $l$ have no marginal affect on surplus as the behavior of the procurer is unaffected and the procurer occupies state $\mathbf{M}_{i}$ for some $i$ with probability 1 in equilibrium.

Similarly, if $a=1$ and $l=0$ as in Lewis and Yildirim (2002) the steady-state distribution of states is degenerate. The analysis to follow summarized in Propositions 6-11 precludes this possibility.

${ }^{28}$ Boyer and Moreaux (1997) discuss the supply as well as strategic benefits to greater flexibility afforded firms that adopt FMSs.

${ }^{29}$ These steady-state surpluses are calculated as in Equation (8) by multiplying the steady-state probability of occupying a particular state by the surplus in that state and summing over all possible states. 
Proposition 7. For the outsourcing equilibrium when $\Delta / \bar{c}$ is small $\frac{\partial W^{o *}}{\partial a}, \frac{\partial B^{o *}}{\partial a}>$ 0 and $\frac{\partial W^{o *}}{\partial l}, \frac{\partial B^{o *}}{\partial l}<0$ for $s c^{o}(a, l) \in[0,2 \bar{c}) \cdot{ }^{30}$

Proposition 7 shows the variation in steady-state total surplus and buyer's surplus for changes in the learning rate is skill loss rate are qualitatively the same for the integrated buyer and outsourcer when the relative skill differential $\Delta / \bar{c}$ is small. This occurs because switching costs are insignificant relative to the variation in random production costs $c_{i}$ arising between suppliers. This implies the buyer switches producers often to access the lowest cost supply source in each period. Thus any factor reducing the costs of switching, such as rapid learning and persistence of knowledge, not only increases total surplus, but also benefits the outsourcer.

Proposition 7 suggests that skill differentials must increase relative to production cost variation before one notes qualitatively different behavior between the outsourcer and the integrated buyer. When $\Delta / \bar{c}$ becomes large, one substantive difference regards the social and private value of learning.

Proposition 8. When $\Delta / \bar{c}$ is sufficiently large, the social value of faster learning is negative, $\frac{\partial W^{o *}}{\partial a} \leq 0$, in an outsourcing equilibrium. The private value of learning to the buyer is positive, $\frac{\partial B^{o *}}{\partial a}>0$, whenever $\lambda_{i}\left(\mathbf{M}_{i}\right) \leq 1$.

Although it is surprising that faster learning may reduce total surplus, this readily follows as a result of the outsourcer's inefficient behavior. When the skill differential is relatively large, it is inefficient to switch from the skilled to the unskilled supplier, yet the outsourcing buyer does occasionally switch to limit the profits of the skilled supplier. ${ }^{31}$ This inefficient behavior increases with more rapid learning that drives down the switching cost for the outsourcer. Consequently total surplus declines with faster learning. Moreover, the buyer's surplus is increasing with faster learning, even though total surplus is declining. This is because the buyer's bargaining position vis-à-vis suppliers is enhanced. Suppliers offer greater price concessions to win the current auction, for if they lose, their opponent is more likely to acquire a skill advantage when learning is faster.

Proposition 8 shows the outsourcer may overvalue learning from a social perspective. We find, ironically the outsourcer may undervalue skill persistence.

Proposition 9. In an outsourcing equilibrium, total surplus is maximized at $l=0$, whereas buyer's surplus is maximized at $l=1$ when $\Delta / \bar{c}$ is large.

\footnotetext{
${ }^{30}$ When $s c^{o}(a, l)=2 \bar{c}$ variations in $a$ and $l$ have no marginal affect on surplus as the behavior of the procurer is unaffected and the procurer occupies state $\mathbf{M}_{i}$ for some $i$ with probability 1 in equilibrium.

${ }^{31}$ Although the analyses are not directly comparable, the possibility of faster learning decreasing social surplus contrasts with Lewis and Yildirim (2002), who find social surplus always increases as higher skill states are achieved. The different effects of learning on social surplus reflect the different responses of the procurer in environments where learning is slow and where it is rapid as in Lewis and Yildirim (2002).
} 
Proposition 9 is illustrated in Figure 1 for the example $(a=0.5, \delta=0.90, \Delta=$ $\bar{c}=1, v(u)=1$ ). Figure 1 (a) shows how total surplus achieves a maximum where $l=0$. From $l=0$ total surplus sharply declines over a range with increases in $l$ and then rises slightly thereafter. The initial decline in total surplus arises from the direct effect of skill loss that causes the buyer to occupy lower skill states where total surplus is smaller. Eventually, though, total surplus increases as $l$ grows because the buyer's cost of switching rises sufficiently to cause a reduction in excess switching, which increases efficiency. ${ }^{32}$

Figure 1(b) shows that, in contrast to total surplus, buyers' surplus reaches its maximum at $l=1$. The explanation is that when $\Delta / \bar{c}$ is large, switching arises infrequently. In the long run, most of the time the buyer occupies skill state $\mathbf{M}$, where there is one skilled and one unskilled supplier. This means when $l$ is large, the buyer can credibly threaten the skilled seller with large loses unless he offers a price concession to win the current auction. Since the incumbent supplier is likely to lose his skill advantage whenever the buyer is not employing his input he submits to the buyer's threat by lowering his price. This intuition is confirmed in Figure 1(c), which shows supplier surplus declining with $l$.

Combining the contrasting predictions of Propositions 6 and 9 suggests some testable predictions of how the technology and organization of integrated buyers and outsourcers should differ when skill cost differentials are large. Whereas the integrated firm will adopt a flexible technology to employ different types of inputs, the outsourcer will select dedicated production processes that must be adjusted and reconfigured to switch from one input to another. Along organization lines, the integrated firm will document best procedures for input use and will maintain in-house expertise to employ different types of operating systems, machines, and software. In contrast there will be less incentive for the outsourcer to commit to these measures for retaining operating knowledge of idle inputs. Also, the integrated firm will wish to build organizational memory to recall best practice procedures for employing different types of inputs. Studies by Argote et al. (1990), Benkard (2000), Darr et al. (1995), and Greenstein (1997) indicate buyers may aggressively pursue a variety of strategies including maintaining a stable workforce, carefully documenting operating procedures, and adopting gateways between different operating systems in order to maintain organizational memory.

\section{COMPARING BENEFITS OF INPUT COMPATIBILITY}

Suppose rival suppliers may determine how compatible their inputs are with each other. With inputs that are utilized in a similar way, the buyer's skill acquired in operating one input may transfer to the other input. That is, there might be diffusion of knowledge and skill between different inputs. Knowing this, would the integrated buyer or outsourcer require suppliers to design inputs to be compatible? Would rival suppliers voluntarily provide compatible products?

\footnotetext{
32 This suggests in the setting of Lewis and Yildirim (2002), suppliers would collectively benefit if they could commit to losing their skill whenever they are inactive. This would reduce the rivalry between suppliers and enable them to earn greater rents.
} 
(a)

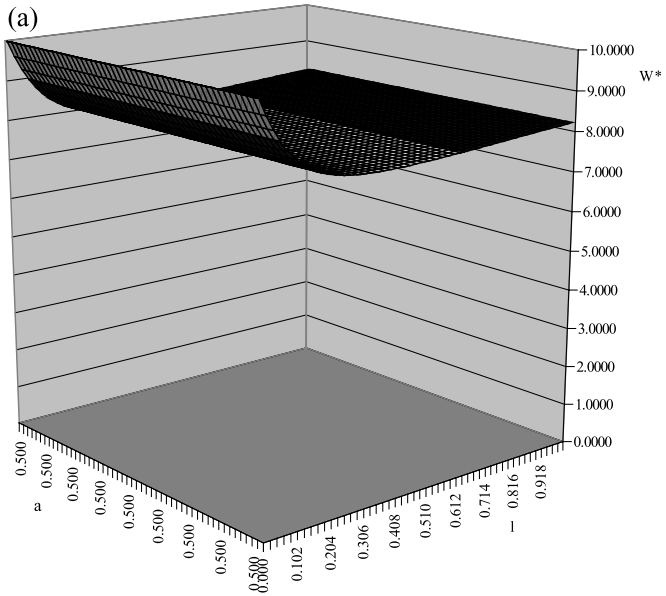

(b)
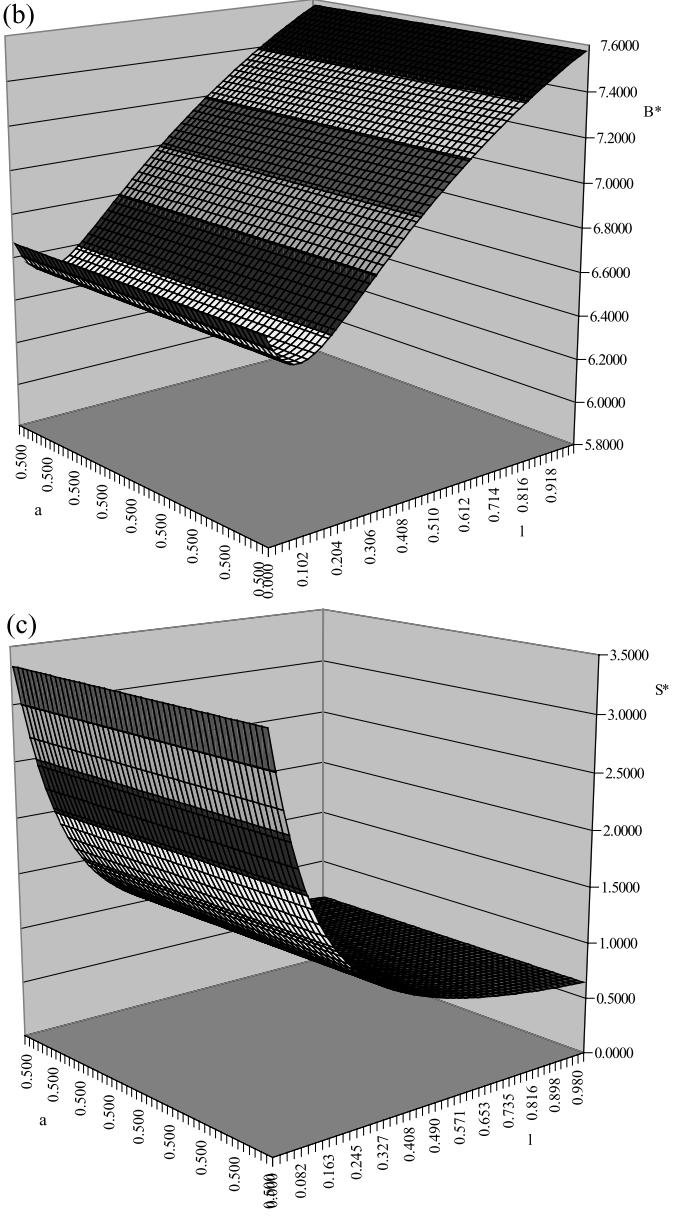

FIGURE 1

EFFECTS OF SKILL LOSS ON TOTAL, BUYER'S, AND SUPPLIER'S SURPLUS. 
Standard theory of oligopoly with switching costs suggests buyers might benefit from purchasing compatible inputs with small switching costs. The theory further suggests that for a fixed market demand, suppliers would resist making their products more compatible to avoid directly competing with each other. ${ }^{33}$

To examine the effects of compatibility on procurement we extend our analysis to assume inputs are compatible and there is learning diffusion. This model of diffusion builds on our previous analysis so we informally describe the model here and summarize our findings. (The formal model is given in Appendix B.)

We assume procurement proceeds as before. However, now a buyer skilled with one of the inputs may also acquire skill with the other, previously unskilled input, with some probability $\gamma \in[0,1]$. Further, diffusion of knowledge between inputs occurs irrespective of the input the buyer currently employs. Proceeding as before we find a unique MPE exists for the integrated buyer and the outsourcer. Further, the qualitative properties of these equilibria are the same when $\Delta / \bar{c}$ is small. In particular, we find as the inputs become more compatible, as measured by $\gamma$, the buyer surplus increases and procurement becomes more efficient. We summarize these findings for the outsourcer in the following proposition:

Proposition 10. Given Condition (A) a unique MPE exists for the outsourcer with the properties that (a) $\frac{d s c^{o}}{d \gamma}>0,(b) \frac{d W^{o *}}{d \gamma}>0$, and (c) $\frac{d B^{o *}}{d \gamma}>0$ for $\Delta / \bar{c}$ small.

Proposition 10, part (a), indicates switching costs are increasing and the probability of switching is decreasing in the diffusion rate. The rationale is that the benefits from switching from the skilled input decline with diffusion. Continuing to use the skilled input enables the buyer to acquire skill with the other input. This opportunity may be lost if the skilled input is not used. Consequently there is less switching from the skilled input, and the buyer is more likely to acquire skill with both inputs. The procurer will transition to higher skill states with correspondingly higher total surplus as reflected by part (b) of the proposition. The buyer will also benefit from diffusion when $\Delta / \bar{c}$ is small as indicated by part (c).

Although input compatibility benefits the outsourcer when $\Delta / \bar{c}$ is small, this is reversed when the skill differential is large.

\section{Proposition 11. When $\Delta / \bar{c}$ is large, $\frac{d W^{o *}}{d \gamma}>0, \frac{d B^{o *}}{d \gamma}<0$, and $\frac{d S u^{o *}}{d \gamma}>0$.}

These findings seem counterintuitive, at least at first glance. After all, with greater compatibility the skill acquired with one input is transferred with higher probability to other inputs. This means in the long run the procurer will occupy higher skill states on average, which should increase his expected surplus. It would also appear that suppliers with inputs that are close substitutes would compete harder, thus reducing supplier's surplus and increasing buyer's surplus.

However, this reasoning overlooks the fact that buyers' bargaining power erodes as inputs become more compatible. With diffusion of knowledge between skilled

\footnotetext{
${ }^{33}$ Suppliers may opt for product compatibility, however, to increase the overall demand for their products.
} 
(a)

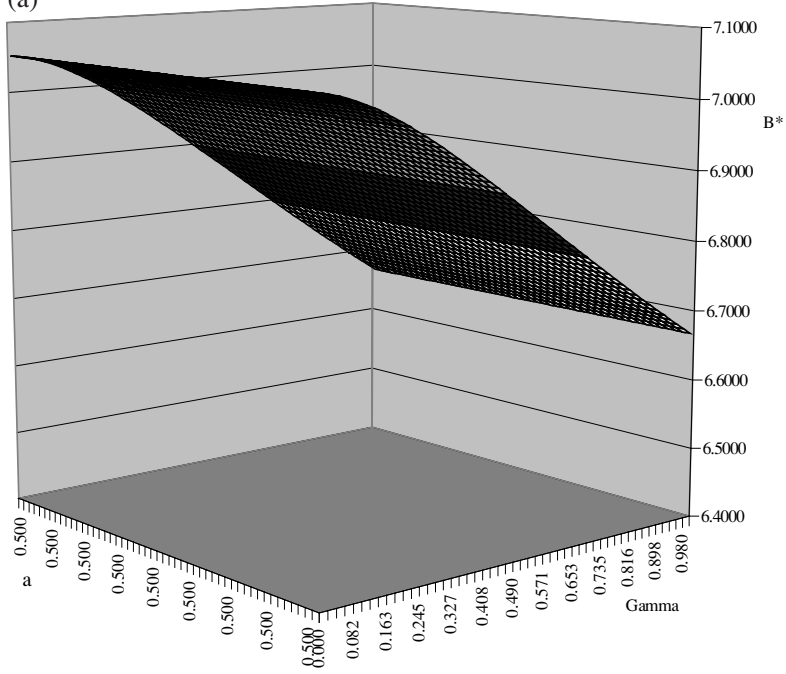

(b)

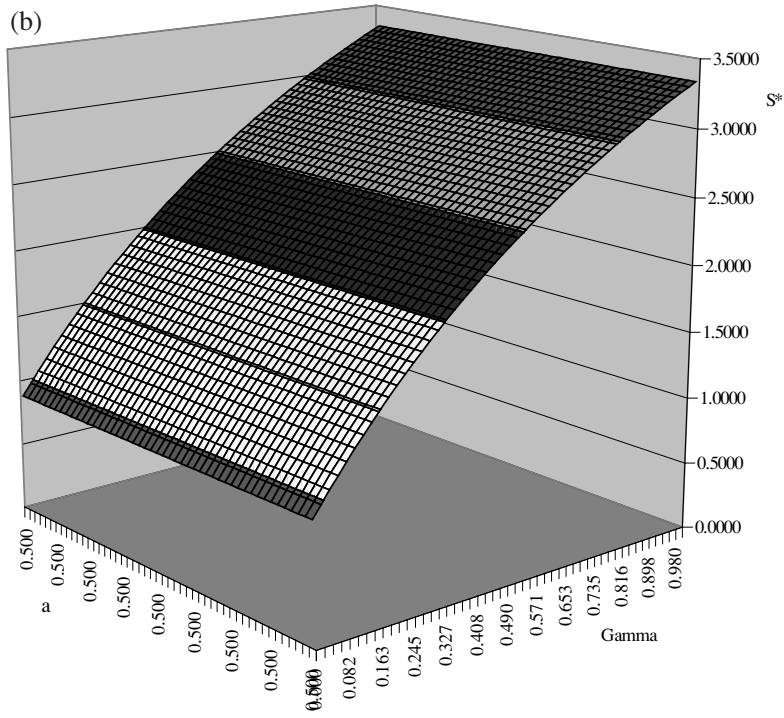

Figure 2

EFFECTS OF LEARNING DIFFUSION ON BUYER'S AND SUPPLIER'S SURPLUS.

and unskilled inputs, the costs of losing and the benefits of winning the next procurement are diminished for each supplier. The winning supplier acquires a smaller skill advantage, as the buyer is more likely to acquire skill with the other input through diffusion. Suppliers will bid less aggressively and supply prices will rise. Further, the rate of increase in supply price will be on the order of $\Delta$, the skill differential, as the diffusion rate increases. This price increase will swamp whatever benefits buyers derive from being in higher skill states, when $\Delta$ is large. Consequently buyer surplus is reduced as inputs become closer substitutes and 
diffusion increases. Suppliers, on the other hand, enjoy greater surplus. ${ }^{34}$ The effects of diffusion on buyer's and supplier's surplus are illustrated for the example $(a=l=0.5, \Delta=\bar{c}=1, v(u)=1)$ in Figure 2.

\section{CONCLUSION}

Our analysis predicts that outsourcers benefit when switching costs are large by threatening to displace incumbent suppliers to induce more competitive pricing. The "bargain followed by rip-off prices" predicted by two-period analyses of early models do not materialize with multiperiod procurements. And the aversion of outsourcers to switching costs predicted by models with price-taking buyers is reversed when large buyers strategically employ switching to reduce costs of procurement.

Aside from identifying how buyers react, our analysis also predicts integrated buyers and outsourcers will manage switching costs differently in several respects. We demonstrate that outsourcers are likely to switch suppliers too often. Outsourcers will invest too much in acquiring skills, but too little in retaining skill. Outsourcers will discourage standardization and compatibility of inputs, and will select an inflexible technology difficult to adapt for using different inputs. All of these inefficiencies are responses of the outsourcer to extort better terms of trade from their input suppliers.

The analysis we have presented raises additional theoretical issues for consideration in future work. For one, by restricting attention to Markov equilibria with payoff-relevant strategies, we have abstracted from other possibly more collusive supplier behavior that might arise with more general strategy spaces. Extending our model to a richer space of strategies might reveal new insights about the effects of switching costs on competition..$^{35}$

Regarding procurement policy, our analysis presumes the buyer implements the optimal auction each period. Although this is the buyer's preferred shortterm action, this policy is not necessarily optimal overall, because the buyer is unable to commit to a long-term policy. This raises the obvious question: Are there other suboptimal short-term policies that nonetheless perform better over the long term? Cabral and Greenstein (1990) suggest, for instance, that a procurement policy committed to ignore switching costs may induce incumbent suppliers to price more competitively. Other recent proposals, discussed in Kovacic and

\footnotetext{
${ }^{34}$ These findings differ somewhat from Lewis and Yildirim (2002), who find that the buyer sometimes prefers information exchange, when the skill difference between suppliers is sufficiently large. This arises when both suppliers are able to reach their most efficient state given information is shared. Subsequent competition between suppliers is enhanced as the cost gap between suppliers is reduced.

${ }^{35}$ For instance, one possibility is the following history-dependent strategy for suppliers. An entrant supplier agrees to stay out of the market (refuses to participate in the auction) for $t$ periods after a new supplier begins producing, provided the other supplier has followed this strategy in all previous periods. Otherwise each supplier reverts to his MPE strategy (characterized in this article). One can show that the buyer's optimal response will be to offer a small strictly positive payment to the entrant to participate. The entrant will accept the payment, thus deviating from the collusive agreement not to participate. Nonetheless this will increase the expected surplus of the entrant, thereby reducing the buyer's surplus.
} 
Smallwood (1994), for reform of government procurement including dual sourcing, mandatory sharing of information between different suppliers, and multiyear procurement commitments might also be fruitfully be addressed within our model.

Another question for future research is how switching costs affect the boundaries of the firm. The seminal studies of Williamson (1975) and Klein et al. (1978) indicate how buyers may integrate with suppliers to overcome production inefficiencies. However, despite the importance and prevalence of switching costs, organization theorists have not explicitly analyzed how such costs determine the boundaries of the firm. Our analysis suggests switching costs may be less of a problem for outsourcing firms in repeated purchase settings in which suppliers' costs of production are difficult to monitor. The incentives for firms to integrate upstream may, therefore, be smaller and outsourcing may be more prevalent. Our analysis further suggests that vertical integration may be most beneficial when procurements are infrequent so that the threat of switching suppliers is less effective for inducing producers to lower their prices. Other factors affecting firm boundaries will include the compatibility and complexities of the procured items and the degree of flexibility in production.

\section{APPENDIX A}

A.1. Proof of Lemma 1. Employing standard techniques, e.g., Fudenberg and Tirole (1991, chapter 7), one can show that incentive compatibility requires $S u_{i}^{o}\left(\mathbf{x}, c_{i}\right)$ to be decreasing in $c_{i}$. This implies $S u_{i}^{o}\left(\mathbf{x}, c_{i}\right)$ is differentiable almost everywhere. Applying the Envelope Theorem to (IC) implies that

$$
\frac{\partial S u_{i}^{o}\left(\mathbf{x}, c_{i}\right)}{\partial \hat{c}_{i}}=-\lambda_{i}^{o}\left(\mathbf{x}, c_{i}\right)
$$

The second-order condition for truth telling requires $\frac{\partial^{2} S u_{i}^{o}\left(\mathbf{x}, c_{i}\right)}{\partial \hat{c}_{i}^{2}} \leq 0$ or that $\lambda_{i}^{o}\left(\mathbf{x}, c_{i}\right)$ be weakly decreasing in $c_{i}$.

(IR) requires $S u_{i}^{o}(\mathbf{x}, \bar{c})=\delta \sum_{\mathbf{x}^{\prime}} \rho_{\mathbf{x x}^{\prime}}(j) S u_{i}^{o}\left(\mathbf{x}^{\prime}\right)$. Using this as a boundary condition and integrating (A.1) over $c_{i}$ yields

$$
S u_{i}^{o}\left(\mathbf{x}, c_{i}\right)=\delta \sum_{\mathbf{x}^{\prime}} \rho_{\mathbf{x} \mathbf{x}^{\prime}}(j) S u_{i}^{o}\left(\mathbf{x}^{\prime}\right)+\int_{c_{i}}^{\bar{c}} \lambda_{i}^{o}\left(\mathbf{x}, \tilde{c}_{i}\right) d \tilde{c}_{i}
$$

Combining (A.2) and (IC), one can derive the payment function in (1). Taking expectations of both sides of (A.2) with respect to $c_{i}$ and recalling $F\left(c_{i}\right)=\frac{c_{i}}{\bar{c}}$ yield the expression for buyer's expected surplus in (2).

A.2. Proof of Proposition 1. To prove existence and uniqueness of an anonymous MPE requires that we demonstrate there is a unique $s c^{o}(\mathbf{x})$ in each state. For the symmetric states $\mathbf{x}=\mathbf{S}$, $\mathbf{U}$, clearly $s c^{o}(\mathbf{S})=s c^{o}(\mathbf{U})=0$ given anonymity. For $\mathbf{x}=\mathbf{M}_{1}, \mathbf{M}_{2}, s c^{o}\left(\mathbf{M}_{2}\right)=-s c^{o}\left(\mathbf{M}_{1}\right)$ again by anonymity. 
In equilibrium, adding (2) and (4) and recalling that $W^{o}(\mathbf{x}) \equiv B^{o}(\mathbf{x})+S u_{1}^{\mathrm{o}}(\mathbf{x})+$ $S u_{2}^{o}(\mathbf{x})$, we have

$$
W^{o}(\mathbf{x})=E_{c}\left\{\sum_{i=1}^{2}\left[\lambda_{i}^{o}(\mathbf{x}, \mathbf{c}) z_{i}^{o}\left(\mathbf{x}, c_{i}\right)\right]\right\}
$$

where $z_{i}^{o}\left(\mathbf{x}, c_{i}\right) \equiv v\left(x_{i}\right)-c_{i}+\delta \sum_{\mathbf{x}^{\prime}} \rho_{\mathbf{x x}^{\prime}}(i) W^{o}\left(\mathbf{x}^{\prime}\right), \lambda_{2}^{o}(\mathbf{x}, \mathbf{c})=1-\lambda_{1}^{o}(\mathbf{x}, \mathbf{c})$, and

$$
\lambda_{1}^{o}(\mathbf{x}, \mathbf{c})= \begin{cases}1, & \text { if } c_{1} \leq c_{2}+\frac{s c^{o}(\mathbf{x})}{2} \\ 0, & \text { otherwise }\end{cases}
$$

For $\mathbf{x}=\mathbf{S}$, since $s c^{o}(\mathbf{S})=0$ and $\sum_{\mathbf{x}^{\prime}} \rho_{\mathbf{S}, \mathbf{x}^{\prime}}(i) W^{o}\left(\mathbf{x}^{\prime}\right)=(1-l) W^{o}(\mathbf{S})+l W^{o}(\mathbf{M})$, (A.3) implies that

$$
W^{o}(\mathbf{S})=\frac{v(s)-\frac{\bar{c}}{3}+\delta l W^{o}(\mathbf{M})}{1-\delta(1-l)}
$$

Similarly, for $\mathbf{x}=\mathbf{U}$, since $s c^{o}(\mathbf{U})=0$ and $\sum_{\mathbf{x}^{\prime}} \rho_{\mathbf{U}, \mathbf{x}^{\prime}}(i) W^{o}\left(\mathbf{x}^{\prime}\right)=(1-a) W^{o}(\mathbf{U})+$ $a W^{o}(\mathbf{M})$, we have

$$
W^{o}(\mathbf{U})=\frac{v(u)-\frac{\bar{c}}{3}+\delta a W^{o}(\mathbf{M})}{1-\delta(1-a)}
$$

Now consider $\mathbf{x}=\mathbf{M}_{1}$ and let $s c^{o} \equiv s c^{o}\left(\mathbf{M}_{1}\right)$. Since $\lambda_{2}^{o}\left(\mathbf{M}_{1}, \mathbf{c}\right)=1-\lambda_{1}^{o}\left(\mathbf{M}_{1}, \mathbf{c}\right)$ and

$$
s c^{o}\left(\mathbf{M}_{1}\right)=v(s)-v(u)+\delta \sum_{\mathbf{x}^{\prime}} W^{o}\left(\mathbf{x}^{\prime}\right)\left[\rho_{\mathbf{M}_{1} \mathbf{x}^{\prime}}(1)-\rho_{\mathbf{M}_{1} \mathbf{x}^{\prime}}(2)\right]
$$

Equation (A.3) implies

$$
\begin{aligned}
W^{o}\left(\mathbf{M}_{1}\right)= & v(u)+\delta \sum_{\mathbf{x}^{\prime}} W^{o}\left(\mathbf{x}^{\prime}\right) \rho_{\mathbf{M}_{1} \mathbf{x}^{\prime}}(2)+s c^{o} E_{c}\left[\lambda_{1}^{o}\left(\mathbf{M}_{1}, \mathbf{c}\right)\right] \\
& -E_{c}\left[\lambda_{1}^{o}\left(\mathbf{M}_{1}, \mathbf{c}\right) c_{1}+\lambda_{2}^{o}\left(\mathbf{M}_{1}, \mathbf{c}\right) c_{2}\right]
\end{aligned}
$$

Given $F(c)=\frac{c}{\bar{c}}$ and (A.4), we note that $E_{c}\left[\lambda_{1}^{o}\left(\mathbf{M}_{1}, \mathbf{c}\right)\right]=\frac{1}{2}+\frac{s c^{o}}{2 \bar{c}}-\frac{s c^{o 2}}{8 \bar{c}^{2}}$, $E_{c}\left[\lambda_{1}^{o}\left(\mathbf{M}_{1}, \mathbf{c}\right) c_{1}\right]=\frac{\bar{c}}{6}+\frac{s c^{o}}{4}-\frac{s c^{o 3}}{48 \bar{c}^{2}}$, and $E_{c}\left[\lambda_{2}^{o}\left(\mathbf{M}_{1}, \mathbf{c}\right) c_{2}\right]=\frac{\left(2 \bar{c}-s c^{o}\right)^{3}}{48 \bar{c}^{2}}$. Inserting these expected values into (A.8) and using (A.7), we find

$$
W^{o}\left(\mathbf{M}_{1}\right)=\frac{1}{1-\delta}\left\{v(s)-\frac{\bar{c}}{3}-h\left(s c^{o}\right)\right\}
$$

where $h\left(s c^{o}\right) \equiv \frac{s c^{03}}{12 \bar{c}^{2}}-\frac{3 s c^{o 2}}{8 \bar{c}}+\frac{s c^{o}}{2}$ with these properties. 
Properties of $h\left(s c^{o}\right)$ : (1) $\operatorname{Sigh}\left(h\left(s c^{o}\right)\right)=\operatorname{Sign}\left(s c^{o}\right)$, (2) $h\left(s c^{o}\right)$ is strictly increasing for $s c^{o}<\bar{c}$ and strictly decreasing for $\bar{c}<s c^{o}<2 \bar{c}$ with $h(\bar{c})=\frac{5 \bar{c}}{24}$ and $h(2 \bar{c})=\frac{\bar{c}}{6}$.

Using the transition probabilities in Assumption 1, note that $\sum_{\mathbf{x}^{\prime}} W^{o}\left(\mathbf{x}^{\prime}\right) \times$ $\rho_{\mathbf{M}_{1} \mathbf{x}^{\prime}}(2)=[(1-a)(1-l)+a l] W^{o}\left(\mathbf{M}_{1}\right)+(1-a) l W^{o}(\mathbf{U})+a(1-l) W^{o}(\mathbf{S})$. Inserting this into (A.7) and using (A.5) and (A.6) yields another equation for $W^{o}\left(\mathbf{M}_{1}\right)$ :

$$
W^{o}\left(\mathbf{M}_{1}\right)=\frac{1}{1-\delta}\left\{v(s)-\frac{\bar{c}}{3}-g\left(s c^{o}\right)\right\}
$$

where $g\left(s c^{o}\right)=\frac{E-s c^{o}}{D}, E \equiv\left[1+\delta \frac{l(1-a)}{1-\delta(1-a)}\right] \Delta$, and $D \equiv \delta\left[\frac{a(1-l)}{1-\delta(1-l)}+\frac{l(1-a)}{1-\delta(1-a)}\right]$ as defined in the text.

Combining (A.9) and (A.10), $s c^{o}$ solves the following equation:

$$
h\left(s c^{o}\right)-g\left(s c^{o}\right)=0
$$

If $E=0$, then the unique root to (A.11) is $s c^{o}=0$. Assume that $E>0$. Since $h(0)-g(0)=-\frac{E}{D}<0$ and $\lim _{a \rightarrow \infty}[h(a)-g(a)]=\infty$, there exists $a>0$ that solves (A.11). From (A.4), whenever $s c^{o}>2 \bar{c}$, we set $s c^{o}=2 \bar{c}$. The fact that for any $s c^{o}<0, h\left(s c^{o}\right)-g\left(s c^{o}\right)<0$ implies that there is no $s c^{o}<0$ that solves (A.11).

By further inspecting the properties of $h\left(s c^{o}\right)$, one can easily show that the solution to Equation (A.11) is unique for $E>0$ if and only if one of the following conditions holds: (1) $D \leq 16$ or (2) if $D>16$, then either $\left(\frac{3 D}{16}+\frac{3}{2}\right) \bar{c}+$ $\frac{D-16}{48 D} \sqrt{D(D-16)} \bar{c}-E<0$ or $\left(\frac{3 D}{16}+\frac{3}{2}\right) \bar{c}-\frac{D-16}{48 D} \sqrt{D(D-16)} \bar{c}-E>0$. Thus, Condition $\mathrm{A}$ in the text, $D \leq 16$, constitutes a sufficient condition for the uniqueness of the anonymous MPE, and is satisfied for any $a, l \in[0,1]$, and $\delta \in\left[0, \frac{16}{17}\right]$.

A.3. Proof of Proposition 2. Again, by anonymity of MPE, we have $\operatorname{sc}^{I}(\mathbf{S})=$ $s c^{I}(\mathbf{U})=0$. Let $s c^{I} \equiv s c^{I}\left(\mathbf{M}_{1}\right)$. Our objective is to show the existence of a unique $s c^{I} \in[0, \bar{c}]$.

From (7), we have

$$
B^{I}(\mathbf{x})=W^{I}(\mathbf{x})=E_{c}\left\{\sum_{i=1}^{2}\left[\lambda_{i}^{I}(\mathbf{x}, \mathbf{c}) z_{i}^{I}\left(\mathbf{x}, c_{i}\right)\right]\right\}
$$

where $\lambda_{2}^{I}(\mathbf{x}, c)=1-\lambda_{1}^{I}(\mathbf{x}, c)$ and

$$
\lambda_{1}^{I}(\mathbf{x}, c)= \begin{cases}1, & \text { if } c_{1} \leq c_{2}+s c^{I}(\mathbf{x}) \\ 0, & \text { otherwise }\end{cases}
$$


Using (A.12) and (A.13), we find the following value functions for the integrated buyer:

$$
\begin{aligned}
B^{I}(\mathbf{S}) & =\frac{v(s)-\frac{\bar{c}}{3}+\delta l B^{I}(\mathbf{M})}{1-\delta(1-l)} \\
B^{I}(\mathbf{L}) & =\frac{v(u)-\frac{\bar{c}}{3}+\delta a B^{I}(\mathbf{M})}{1-\delta(1-a)} \\
B^{I}(\mathbf{M}) & =\frac{1}{1-\delta}\left\{v(s)-\frac{\bar{c}}{3}-h^{I}\left(s c^{I}\right)\right\} \\
B^{I}(\mathbf{M}) & =\frac{1}{1-\delta}\left\{v(s)-\frac{\bar{c}}{3}-g\left(s c^{I}\right)\right\}
\end{aligned}
$$

where $h^{I}\left(s c^{I}\right) \equiv \frac{\left(s c^{I}\right)^{3}}{6 \bar{c}^{2}}-\frac{3\left(s c^{I}\right)^{2}}{2 \bar{c}}+\frac{s c^{I}}{2}$ and $g(\cdot)$ is defined in (A.10).

Properties of $h^{I}\left(s c^{I}\right)$ : (1) $\operatorname{Sign}\left(h^{I}\left(s c^{I}\right)\right)=\operatorname{Sign}\left(s c^{I}\right)$, (2) $h^{I}\left(s c^{I}\right)$ is strictly increasing for $s c^{I}<\bar{c}$ with $h^{I}(\bar{c})=\frac{\bar{c}}{6}$.

Combining (A.16) and (A.17), $s c^{I}$ solves the following equation:

$$
h^{I}\left(s c^{I}\right)-g\left(s c^{I}\right)=0
$$

A similar argument to that in the proof of Proposition 1 reveals that there exists $s c^{I} \geq 0$ that solves (A.18). From (A.13), we set $s c^{I}=\bar{c}$ whenever the solution to (A.18) is greater than $\bar{c}$. The uniqueness follows from the fact the function $\left[h^{I}\left(s c^{I}\right)-g\left(s c^{I}\right)\right]$ is strictly increasing in $s c^{I}$.

A.4. Proof of Proposition 3. Parts (a) and (b) follow from the proof of Proposition 1 . To prove (c) and (d), we differentiate (A.18) with respect to $l$ and $a$, respectively, and find

$$
\begin{aligned}
{\left[D h^{I \prime}(s c)+1\right] \frac{\partial s c^{I}}{\partial l} } & =\frac{\delta(1-a)}{1-\delta(1-a)}\left[\Delta-h^{I}\left(s c^{I}\right)\right]+\frac{\delta a}{[1-\delta(1-l)]^{2}} h^{I}\left(s c^{I}\right) \\
{\left[D h^{I \prime}\left(s c^{I}\right)+1\right] \frac{\partial s c^{I}}{\partial a} } & =-\left[\frac{\delta(1-l)}{1-\delta(1-l)} h^{I}\left(s c^{I}\right)+\frac{\delta l}{[1-\delta(1-a)]^{2}}\left[\Delta-h^{I}\left(s c^{I}\right)\right]\right]
\end{aligned}
$$

Below, in the proof of Proposition 5, we establish that $B^{I}(\mathbf{M}) \geq B^{I}(\mathbf{U})$, which in turn implies $\Delta-h^{I}\left(s c^{I}\right) \geq 0$. Together with $h^{I \prime}\left(s c^{I}\right)>0$, we have $\frac{\partial s c^{I}}{\partial l} \geq 0$ and $\frac{\partial s c^{I}}{\partial a} \leq 0$. Furthermore, from $F(c)=\frac{c}{\bar{c}}$ and (A.15), $\lambda_{1}^{I}\left(\mathbf{M}_{1} \mid a, l\right)=\frac{1}{2}+\frac{s c^{I}}{\bar{c}}-\frac{\left(s c^{I}\right)^{2}}{2 \bar{c}^{2}}$, and thus $\frac{\partial \lambda_{1}^{I}\left(\mathbf{M}_{1} \mid a, l\right)}{\partial a}=\left[\frac{1}{\bar{c}}-\frac{s c^{I}}{\bar{c}^{2}}\right] \frac{\partial s c^{I}}{\partial a} \leq 0$, and $\frac{\partial \lambda_{1}^{I}\left(\mathbf{M}_{1} \mid a, l\right)}{\partial l}=\left[\frac{1}{\bar{c}}-\frac{s c^{I}}{\bar{c}^{2}}\right] \frac{\partial s c^{I}}{\partial l} \geq 0$. 
Similarly, for the outsourcing case, we differentiate (A.11) with respect to $a$ and $l$, respectively, and find

$$
\begin{aligned}
& {\left[D h^{\prime}\left(s c^{o}\right)+1\right] \frac{\partial s c^{o}}{\partial a}=-\left[\frac{\delta(1-l)}{1-\delta(1-l)} h\left(s c^{o}\right)+\frac{\delta l}{[1-\delta(1-a)]^{2}}\left[\Delta-h\left(s c^{o}\right)\right]\right]} \\
& {\left[D h^{\prime}\left(s c^{o}\right)+1\right] \frac{\partial s c^{o}}{\partial l}=\frac{\delta(1-a)}{1-\delta(1-a)}\left[\Delta-h\left(s c^{o}\right)\right]+\frac{\delta a}{[1-\delta(1-l)]^{2}} h\left(s c^{o}\right)}
\end{aligned}
$$

We establish in the proof of Proposition 5 below that $W^{o}(\mathbf{M}) \geq W^{o}(\mathbf{U})$, which in turn implies that $\Delta-h\left(s c^{o}\right) \geq 0$. Furthermore, since, under Condition $\mathrm{A}$, the solution to (A.11) is unique, we have $D h^{\prime}\left(s c^{o}\right)+1>0$. Together these imply that $\frac{\partial s c^{o}}{\partial a} \leq 0$ and $\frac{\partial s c^{o}}{\partial l} \geq 0$.

Also, from (A.4), one can easily find that $\lambda_{1}^{o}\left(\mathbf{M}_{1} \mid a, l\right)=E_{\mathbf{c}} \lambda_{1}^{o}\left(\mathbf{M}_{1}, \mathbf{c}\right)=\frac{1}{2}+$ $\frac{s c^{o}}{2 \bar{c}}-\frac{\left(s c^{o}\right)^{2}}{8 \bar{c}^{2}}$. Thus, $\frac{\partial \lambda_{1}^{o}\left(\mathbf{M}_{1} \mid a, l\right)}{\partial a}=\left[\frac{1}{2 \bar{c}}-\frac{s c^{o}}{4 \bar{c}^{2}}\right] \frac{\partial s c^{o}}{\partial a} \leq 0$, and $\frac{\partial \lambda_{1}^{o}\left(\mathbf{M}_{1} \mid a, l\right)}{\partial l}=\left[\frac{1}{2 \bar{c}}-\frac{s c^{o}}{4 \bar{c}^{2}}\right] \frac{\partial s c^{o}}{\partial l} \geq$ 0 , completing the proof.

A.5. Proof of Proposition 4. To show $s c^{o}<s c^{I}$, note first that for any $s c^{o} \in[0, \bar{c}], h\left(s c^{o}\right)-h^{I}\left(s c^{o}\right)=\frac{\left(s c^{o}\right)^{2}}{4 \bar{c}}\left[\frac{1}{2}-\frac{s c^{o}}{3 \bar{c}}\right]>0$. Now, suppose by way of contradiction that $s c^{o} \geq s c^{I}$. Since the equilibrium $s c^{o}$ and $s c^{I}$ uniquely solve Equations (A.4) and (A.13), respectively, we have $h\left(s c^{o}\right)=\frac{E-s c^{o}}{D} \leq \frac{E-s c^{I}}{D}=h^{I}\left(s c^{I}\right)$. Furthermore, since $h^{I}(\cdot)$ is increasing, this means $h\left(s c^{o}\right)-h^{I}\left(s c^{I}\right)=h\left(s c^{o}\right)-h^{I}\left(s c^{o}\right)>$ 0 , yielding a contradiction. Hence, $s c^{o}<s c^{I}$. Given (A.4) and (A.13), this further reveals that $\lambda_{1}^{o}\left(\mathbf{M}_{1}\right)<\lambda_{1}^{I}\left(\mathbf{M}_{1}\right)$.

A.6. Proof of Proposition 5. Note from (A.14) and (A.16) that $B^{I}(\mathbf{S})-$ $B^{I}(\mathbf{M})=\frac{h^{I}\left(s c^{I}\right)}{1-\delta(1-l)}$. Thus, $B^{I}(\mathbf{S}) \geq B^{I}(\mathbf{M})\left(\right.$ with $>$ for $\left.s c^{I}>0\right)$. To prove $B^{I}(\mathbf{M}) \geq$ $B^{I}(\mathbf{U})$, suppose, by way of contradiction, $B^{I}(\mathbf{M})<B^{I}(\mathbf{U})$. From (A.14) and (A.16), this implies $\Delta<h^{I}\left(s c^{I}\right)$. Since $h^{I}\left(s c^{I}\right)=g\left(s c^{I}\right)$, this further implies $s c^{I}<E-D(\Delta)$. Let $\zeta \equiv 1-\frac{\delta a(1-l)}{1-\delta(1-l)}$. Then, $E-D(\Delta)=\zeta \Delta$, which means $\zeta \in(0,1]$. We analyze two cases regarding the parameter values

Case 1: $\zeta \Delta-3 \bar{c}>0$.

One can see that this implies $s c^{I}=\bar{c}$. Then, we have $\Delta c<h^{I}\left(s c^{I}\right)=\frac{\bar{c}}{6}$ and $s c^{I}=\bar{c}<\zeta \Delta$, which, in turn, implies $\zeta>6$, yielding a contradiction to $\zeta \in(0,1]$.

Case 2: $\zeta \Delta-3 \bar{c} \leq 0$.

This means $s c^{I}<\bar{c}$. Since $h^{I}\left(s c^{I}\right)$ is strictly increasing in $s c^{I}$, we have $\Delta<$ $h^{I}\left(s c^{I}\right)<h^{I}(\zeta \Delta)$, implying $h^{I}(\zeta \Delta)-\Delta>0$. However, using the definition of $h^{I}$, we find $h^{I}(\zeta \Delta)-\Delta=\Delta\left[\frac{\zeta^{2} \Delta}{2 \bar{c}}\left(\frac{\zeta \Delta}{3 \bar{c}}-1\right)+\frac{\zeta}{2}-1\right] \leq 0$.

Together Case 1 and Case 2 reveal $B^{I}(\mathbf{M}) \geq B^{I}(\mathbf{U})$ (with $>$ for $s c^{I}>0$ ). Thus, $B^{I}(\mathbf{S}) \geq B^{I}(\mathbf{M}) \geq B^{I}(\mathbf{U})$ (with $>$ for $s c^{I}>0$ ). 
Next, we show that $W^{o}(\mathbf{S}) \geq W^{o}(\mathbf{M})$. Together (A.5) and (A.9) imply that $W^{o}(\mathbf{S})-W^{o}(\mathbf{M})=\frac{h\left(s c^{o}\right)}{1-\delta(1-l)}$. Since $h\left(s c^{o}\right) \geq 0$ for any $s c^{o} \geq 0$, the desired result follows.

To prove $W^{o}(\mathbf{M}) \geq W^{o}(\mathbf{U})$, we follow similar steps in the proof of Proposition 3, and suppose by way of contradiction that $W^{o}(\mathbf{M})<W^{o}(\mathbf{U})$. From (A.6) and (A.9), this means $\Delta<h\left(s c^{o}\right)$. Since $h\left(s c^{o}\right)=g\left(s c^{o}\right)$, this also means $s c^{o}<E-D(\Delta)$. Again, let $\zeta \equiv 1-\frac{\delta a(1-l)}{1-\delta(1-l)}$. Then, $E-D(\Delta)=\zeta \Delta$, which implies $\zeta \in[0,1]$. We analyze two cases regarding $\zeta$ and in each case we generate a contradiction by using inequalities $\Delta<h\left(s c^{o}\right)$ and $s c^{o}<\zeta \Delta$.

Case 1: $\frac{E-\bar{c}}{D} \leq h(\bar{c})$.

One can show that for these parameter values $s c^{o} \leq \bar{c}$. Since $h\left(s c^{o}\right)$ is increasing in $s c^{o}$ whenever $s c^{o} \leq \bar{c}$, it must be that $\Delta<h\left(s c^{o}\right)<h(\zeta \Delta)$ or $h(\zeta \Delta)-\Delta>$ 0 . Using the functional form for $h\left(s c^{o}\right)$ in (A.9), this implies the polynomial $J\left(\frac{\Delta}{\bar{c}}\right) \equiv$ $\frac{\zeta^{3}}{12}\left(\frac{\Delta}{\bar{c}}\right)^{2}-\frac{3 \zeta^{2}}{8}\left(\frac{\Delta}{\bar{c}}\right)+\frac{\zeta}{2}-1>0$. However, given $E-\bar{c} \leq \frac{5 D}{24} \bar{c}$ and $\zeta \in[0,1]$, one can show that $J\left(\frac{\Delta}{\bar{c}}\right) \leq 0$, yielding a contradiction.

Case 2: $\frac{E-\bar{c}}{D} \geq h(\bar{c})$ and $\frac{E-2 \bar{c}}{D} \leq h(2 \bar{c})$.

This implies $\bar{c} \leq s c^{o} \leq 2 \bar{c}$. Moreover, $h\left(s c^{o}\right)$ is decreasing in $s c^{o}$ in this region. This means $\Delta<\bar{h}\left(s c^{o}\right) \leq h(\bar{c})=\frac{5}{24} \bar{c}$ or $\frac{\Delta}{\bar{c}}<\frac{5}{24}$. Also, since $\bar{c} \leq s c^{o}<\zeta \Delta$, we have $\frac{1}{\zeta}<\frac{\Delta}{\bar{c}}<\frac{5}{24}$, implying $\zeta>1$. This contradicts $\zeta \in[0,1]$.

Hence, $W^{o}(\mathbf{M}) \geq W^{o}(\mathbf{U})$. This completes the proof of part (b).

Next, for convenience, we first prove parts (d) and (e), and then part (c). We determine suppliers' expected surplus in each state by using (2). Since the equilibrium is symmetric, w.l.o.g. we consider only supplier 1. We start with $\mathbf{x}=\mathbf{M}_{2}$. Note first that $\sum_{\mathbf{x}^{\prime}} \rho_{\mathbf{M}_{2} \mathbf{x}^{\prime}}(2) S u_{1}\left(\mathbf{x}^{\prime}\right)=S u_{1}\left(\mathbf{M}_{2}\right)$ and $E_{c}\left[\lambda_{1}^{o}\left(\mathbf{M}_{2}, \mathbf{c}\right) c_{1}\right]=\frac{\bar{c}}{6}-b\left(s c^{o}\right)$, where $b\left(s c^{o}\right) \equiv \frac{\left(s c^{o}\right)^{3}}{48 \bar{c}^{2}}-\frac{\left(s c^{o}\right)^{2}}{8 \bar{c}}+\frac{s c^{o}}{4}$. From (2), we then have

$$
S u_{1}\left(\mathbf{M}_{2}\right)=\frac{1}{1-\delta}\left[\frac{\bar{c}}{6}-b\left(s c^{o}\right)\right]
$$

For $\quad \mathbf{x}=\mathbf{S}, \quad$ since $\quad \sum_{\mathbf{x}^{\prime}} \rho_{\mathbf{S x}^{\prime}}(2) S u_{1}\left(\mathbf{x}^{\prime}\right)=(1-l) S u_{1}(\mathbf{S})+l S u_{1}\left(\mathbf{M}_{2}\right) \quad$ and $E_{c}\left[\lambda_{1}^{o}(\mathbf{S}, \mathbf{c}) c_{1}\right]=\frac{\bar{c}}{6}$, we have

$$
S u_{1}(\mathbf{S})=\frac{\frac{\bar{c}}{6}+\delta l S u_{1}\left(\mathbf{M}_{2}\right)}{1-\delta(1-l)}
$$

Similarly, for $\mathbf{x}=\mathbf{U}$, since $\sum_{\mathbf{x}^{\prime}} \rho_{\mathbf{U x}^{\prime}}(2) S u_{1}\left(\mathbf{x}^{\prime}\right)=(1-a) S u_{1}(\mathbf{U})+a S u_{1}\left(\mathbf{M}_{2}\right)$ and $E_{c}\left[\lambda_{1}^{o}(\mathbf{U}, c) c_{1}\right]=\frac{\bar{c}}{6}$, we have

$$
S u_{1}(\mathbf{U})=\frac{\frac{\bar{c}}{6}+\delta a S u_{1}\left(\mathbf{M}_{2}\right)}{1-\delta(1-a)}
$$


Finally, for $\mathbf{x}=\mathbf{M}_{1}$, since $\sum_{\mathbf{x}^{\prime}} \rho_{\mathbf{M}_{1} \mathbf{x}^{\prime}}(2) S u_{1}\left(\mathbf{x}^{\prime}\right)=(1-a)(1-l) S u_{1}\left(\mathbf{M}_{1}\right)+$ $(1-a) l S u_{1}(\mathbf{L})+a(1-l) S u_{1}(\mathbf{S})+a l S u_{1}\left(\mathbf{M}_{2}\right)$ and $E_{c}\left[\lambda_{1}^{o}\left(\mathbf{M}_{1}, \mathbf{c}\right) c_{1}\right]=\frac{\bar{c}}{6}+\frac{s c^{o}}{4}-$ $\frac{\left(s c^{0}\right)^{3}}{48 \bar{c}^{2}}$, Equation (2) implies

$$
\begin{aligned}
S u_{1}\left(\mathbf{M}_{1}\right)= & \frac{1}{1-\delta(1-a)(1-l)} \\
& \times\left\{\begin{array}{c}
\delta\left[(1-a) l S u_{1}(\mathbf{U})+a(1-l) S u_{1}(\mathbf{S})+a l S u_{1}\left(\mathbf{M}_{2}\right)\right] \\
+\frac{\bar{c}}{6}+\frac{s c^{o}}{4}-\frac{\left(s c^{o}\right)^{3}}{48 \bar{c}^{2}}
\end{array}\right\}
\end{aligned}
$$

To prove part (e), we use (A.20) and (A.21) to find $S u_{1}(\mathbf{S})-S u_{1}(\mathbf{U})=$ $\frac{\delta(a-l) b\left(s c^{o}\right)}{[1-\delta(1-l)][1-\delta(1-a)]}$. Since $b\left(s c^{o}\right)>0$ for any $s c^{o}>0$, we conclude that $\operatorname{Sign}\left(S u_{1}(\mathbf{H})-S u_{1}(\mathbf{L})\right)=\operatorname{Sign}(a-l)$. Furthermore, since, by symmetry, $S u_{1}(\mathbf{S})=$ $S u_{2}(\mathbf{S})$ and $S u_{1}(\mathbf{U})=S u_{2}(\mathbf{U})$, the result follows.

Similarly, to prove part (d), we use (A.19), (A.20), and (A.21) to find $S u_{1}(\mathbf{S})-$ $S u_{1}\left(\mathbf{M}_{2}\right)=\frac{b\left(s c^{o}\right)}{1-\delta(1-l)}$ and $S u_{1}(\mathbf{U})-S u_{1}\left(\mathbf{M}_{2}\right)=\frac{b\left(s c^{o}\right)}{1-\delta(1-a)}$. Again, since $b\left(s c^{o}\right)>0$ for any $s c^{o}>0$, we have $S u_{1}\left(\mathbf{M}_{2}\right) \leq \min \left\{S u_{1}(\mathbf{U}), S u_{1}(\mathbf{S})\right\}$.

For part (c), using (A.20), (A.21), and (A.22), we have

$$
\begin{aligned}
S u_{1}\left(\mathbf{M}_{1}\right)-S u_{1}(\mathbf{S})= & \frac{1}{1-\delta(1-a)(1-l)} \\
& \times\left[\delta l(1-a)\left(S u_{1}(\mathbf{U})-S u_{1}\left(\mathbf{M}_{2}\right)\right)+\frac{s c^{o}}{4}-\frac{\left(s c^{o}\right)^{3}}{48 \bar{c}^{2}}\right] \\
S u_{1}\left(\mathbf{M}_{1}\right)-S u_{1}(\mathbf{U})= & \frac{1}{1-\delta(1-a)(1-l)} \\
& \times\left[\delta a(1-l)\left(S u_{1}(\mathbf{S})-S u_{1}\left(\mathbf{M}_{2}\right)\right)+\frac{s c^{o}}{4}-\frac{\left(s c^{o}\right)^{3}}{48 \bar{c}^{2}}\right]
\end{aligned}
$$

Since $\frac{s c^{o}}{4}-\frac{\left(s c^{o}\right)^{3}}{48 \bar{c}^{2}} \geq 0$ for any $s c^{o} \in[0,2 \bar{c}]$ and $S u_{1}\left(\mathbf{M}_{2}\right) \leq \min \left\{S u_{1}(\mathbf{U}), S u_{1}(\mathbf{S})\right\}$, these equations imply that $S u_{1}\left(\mathbf{M}_{1}\right) \geq \max \left\{S u_{1}(\mathbf{L}), S u_{1}(\mathbf{H})\right\}$.

Finally, to prove part (c), we first note the following useful identity:

$$
\begin{aligned}
\Gamma(a, l, \delta) \equiv & \frac{\delta a l}{1-\delta(1-a)(1-l)}\left[\frac{1}{1-\delta(1-a)}+\frac{1}{1-\delta(1-l)}-1\right] \\
& +\frac{1-\delta}{1-\delta(1-a)(1-l)}(D+1) \\
= & 1 \text { for all } a, l, \delta
\end{aligned}
$$

$$
\begin{aligned}
& B(\mathbf{S})-B(\mathbf{M}) \\
& \quad=\left[W^{o}(\mathbf{S})-S u_{1}(\mathbf{S})-S u_{2}(\mathbf{S})\right]-\left[W^{o}(\mathbf{M})-S u_{1}\left(\mathbf{M}_{1}\right)-S u_{2}\left(\mathbf{M}_{1}\right)\right]
\end{aligned}
$$




$$
\begin{aligned}
= & \frac{1}{1-\delta}[\Gamma(a, l, \delta)-1] \frac{\bar{c}}{6}+\frac{1}{1-\delta(1-a)(1-l)}\left(\frac{s c^{o}}{4}-\frac{s c^{o 3}}{48 \bar{c}^{2}}\right) \\
& +\frac{1}{1-\delta}\left\{\frac{\delta l}{1-\delta(1-l)}\left(2 b\left(s c^{o}\right)-h\left(s c^{o}\right)\right)+\left(h\left(s c^{o}\right)-b\left(s c^{o}\right)\right)\right. \\
& \left.\quad-\frac{\delta a l}{1-\delta(1-a)(1-l)}\left[\frac{1}{1-\delta(1-a)}+\frac{1}{1-\delta(1-l)}-1\right] b\left(s c^{o}\right)\right\} \\
\geq & \frac{1}{1-\delta}\left\{\frac{\delta l}{1-\delta(1-l)}\left(2 b\left(s c^{o}\right)-h\left(s c^{o}\right)\right)+\left(h\left(s c^{o}\right)-b\left(s c^{o}\right)\right)\right. \\
= & \left.\left.\frac{1}{1-\delta}\left\{\frac{\delta l}{1-\delta(1-l)} b\left(s c^{o}\right)\right\}+\frac{1}{1-\delta(1-l)}\left(h\left(s c^{o}\right)-b\left(s c^{o}\right)\right)\right\}+\frac{s c^{o}}{1-\delta(1-a)(1-l)}-\frac{s c^{o 3}}{48 \bar{c}^{2}}\right) \\
\geq & 0\left(\frac{s c^{o}}{4}-\frac{s c^{o 3}}{48 \bar{c}^{2}}\right)
\end{aligned}
$$

Similarly,

$$
\begin{aligned}
B(\mathbf{M})-B(\mathbf{L}) & \\
= & {\left[W^{o}(\mathbf{M})-S u_{1}\left(\mathbf{M}_{1}\right)-S u_{2}\left(\mathbf{M}_{1}\right)\right]-\left[W^{o}(\mathbf{L})-S u_{1}(\mathbf{L})-S u_{2}(\mathbf{L})\right] } \\
= & \frac{1}{1-\delta}[1-\Gamma(a, l, \delta)] \frac{\bar{c}}{6}+\frac{\Delta c}{1-\delta(1-a)}-\frac{\delta a}{(1-\delta)[1-\delta(1-a)]}\left(2 b\left(s c^{o}\right)-h\left(s c^{o}\right)\right) \\
& +\frac{1}{1-\delta}\left\{\frac{\delta a l}{1-\delta(1-a)(1-l)}\left[\frac{1}{1-\delta(1-a)}+\frac{1}{1-\delta(1-l)}-1\right]\right. \\
= & \frac{1}{1-\delta}\left\{\frac{\left.\delta\left(s c^{o}\right)-\left(b\left(s c^{o}\right)-h\left(s c^{o}\right)\right)\right\}-\frac{1}{1-\delta(1-a)(1-l)}\left(\frac{s c^{o}}{4}-\frac{s c^{o 3}}{48 \bar{c}^{2}}\right)}{1-\delta(1-a)(1-l)}\left[\frac{1}{1-\delta(1-a)}+\frac{1}{1-\delta(1-l)}-1\right]+1\right. \\
& +\frac{1}{1-\delta}\left\{-1+\frac{\delta a}{1-\delta(1-a)}-\frac{\delta(1-\delta)}{1-\delta(1-a)(1-l)}\right\} b\left(s c^{o}\right)
\end{aligned}
$$

Note that

$$
\begin{aligned}
\frac{\Delta}{1-\delta(1-a)} & =E+\frac{\delta(1-l)(1-a)}{1-\delta(1-a)} \Delta c \\
& =D h\left(s c^{o}\right)+s c^{o}+\frac{\delta(1-l)(1-a)}{1-\delta(1-a)} \Delta \text { from (A.11) }
\end{aligned}
$$


Thus,

$$
\begin{aligned}
B(\mathbf{M})-B(\mathbf{L})= & \frac{1}{1-\delta}\left\{\frac{\delta a l}{1-\delta(1-a)(1-l)}\left[\frac{1}{1-\delta(1-a)}+\frac{1}{1-\delta(1-l)}-1\right]+1\right. \\
& \left.\quad-\frac{2 \delta a}{1-\delta(1-a)}-\frac{3(1-\delta)}{1-\delta(1-a)(1-l)}\right\} b\left(s c^{o}\right) \\
& +\left\{D-\frac{\delta(1-a) l}{[1-\delta(1-a)][1-\delta(1-a)(1-l)]}\right\} h\left(s c^{o}\right)+s c^{o} \\
& +\frac{\delta(1-l)(1-a)}{1-\delta(1-a)} \Delta \\
\geq & \frac{1}{1-\delta}\{1-3(1-\delta)\} b\left(s c^{o}\right)+s c^{o} \\
= & \frac{1}{1-\delta} b\left(s c^{o}\right)+s c^{o}-3 b\left(s c^{o}\right) \\
\geq & 0\left(>0 \text { when } s c^{o}>0\right)
\end{aligned}
$$

A.7. Proof of Proposition 6. From (9), the steady-state probabilities are found from the following system of equations:

(A.23) $\left[\lambda_{1}^{I}(\mathbf{x}) \rho_{\mathbf{x}^{\prime} \mathbf{x}}(1)+\lambda_{2}^{I}(\mathbf{x}) \rho_{x^{\prime} x}(2)\right] \cdot \gamma^{I}=\gamma^{I} \quad$ for all $\mathbf{x}, \mathbf{x}^{\prime} \in\left\{\mathbf{S}, \mathbf{M}_{1}, \mathbf{M}_{2}, \mathbf{U}\right\}$

where $\gamma^{I \prime}=\left(\gamma_{\mathbf{S}}^{I}, \gamma_{\mathbf{M}_{1}}^{I}, \gamma_{\mathbf{M}_{2}}^{I}, \gamma_{\mathbf{U}}^{I}\right)$ and $\gamma_{\mathbf{S}}^{I}+\gamma_{\mathbf{M}_{1}}^{I}+\gamma_{\mathbf{M}_{2}}^{I}+\gamma_{\mathbf{U}}^{I}=1$.

Solving (A.23) for $\gamma^{I}$ yields

$$
\begin{aligned}
& \gamma_{\mathbf{S}}^{I}(a, l)=\frac{a^{2}(1-l)\left(1-\lambda^{I}\left(\mathbf{M}_{1} \mid a, l\right)\right)}{\left(1-\lambda^{I}\left(\mathbf{M}_{1} \mid a, l\right)\right) \Omega(a, l)+a l} \\
& \gamma_{\mathbf{M}_{1}}^{I}(a, l)=\gamma_{\mathbf{M}_{2}}^{I}(a, l)=\frac{1}{2} \frac{a l}{\left(1-\lambda^{I}\left(\mathbf{M}_{1} \mid a, l\right)\right) \Omega(a, l)+a l} \\
& \gamma_{\mathbf{U}}^{I}(a, l)=\frac{l^{2}(1-a)\left(1-\lambda^{I}\left(\mathbf{M}_{1} \mid a, l\right)\right)}{\left(1-\lambda^{I}\left(\mathbf{M}_{1} \mid a, l\right)\right) \Omega(a, l)+a l}
\end{aligned}
$$

where $\Omega(a, l) \equiv(1-a) l^{2}+(1-l) a^{2}$.

Now recall that the long-run surplus for the integrated buyer is given by

$$
B^{I *}(a, l)=\gamma_{\mathbf{S}}^{I}(a, l) B^{I}(\mathbf{S})+\gamma_{\mathbf{M}_{1}}^{I}(a, l) B^{I}\left(\mathbf{M}_{1}\right)+\gamma_{\mathbf{M}_{2}}^{I}(a, l) B^{I}\left(\mathbf{M}_{2}\right)+\gamma_{\mathbf{U}}^{I}(a, l) B^{I}(\mathbf{U})
$$

Since $\gamma_{\mathbf{S}}^{I}+\gamma_{\mathbf{M}_{1}}^{I}+\gamma_{\mathbf{M}_{2}}^{I}+\gamma_{\mathbf{U}}^{I}=1$ and $B^{I}\left(\mathbf{M}_{1}\right)=B^{I}\left(\mathbf{M}_{2}\right)=B^{I}(\mathbf{M})$ by anonymity, we can rewrite (A.25) as 


$$
\begin{aligned}
B^{I *}(a, l)= & B^{I}(\mathbf{M})+\gamma_{\mathbf{U}}^{I}(a, l)\left[B^{I}(\mathbf{U})-B^{I}(\mathbf{M})\right] \\
& +\gamma_{\mathbf{S}}^{I}(a, l)\left[B^{I}(\mathbf{S})-B^{I}(\mathbf{M})\right]
\end{aligned}
$$

Using (A.14), (A.15), and (A.16), we have

$$
\begin{aligned}
& B^{I}(\mathbf{U})-B^{I}(\mathbf{M})=\frac{1}{1-\delta(1-a)}\left[h^{I}\left(s c^{I}\right)-\Delta\right] \\
& B^{I}(\mathbf{S})-B^{I}(\mathbf{M})=\frac{1}{1-\delta(1-l)} h^{I}\left(s c^{I}\right)
\end{aligned}
$$

Inserting (A.27) into (A.26) yields

(A.28)

$$
\begin{aligned}
B^{I *}(a, l)= & \frac{1}{1-\delta}\left\{v-c(s)-\frac{\bar{c}}{3}-h^{I}\left(s c^{I}\right)\right\}+\gamma_{\mathbf{U}}^{I}(a, l) \frac{1}{1-\delta(1-a)}\left[h^{I}\left(s c^{I}\right)-\Delta\right] \\
& +\gamma_{\mathbf{S}}^{I}(a, l) \frac{1}{1-\delta(1-l)} h^{I}\left(s c^{I}\right)
\end{aligned}
$$

Differentiating (A.28) with respect to $l$ and $a$, respectively, reveals the following expressions:

(A.29)

$$
\begin{aligned}
\frac{\partial B^{I *}(a, l)}{\partial l}= & {\left[-\frac{1}{1-\delta}+\frac{\gamma_{\mathbf{U}}^{I}}{1-\delta(1-a)}+\frac{\gamma_{\mathbf{S}}^{I}}{1-\delta(1-l)}\right] h^{I \prime}\left(s c^{I}\right) \frac{\partial s c^{I}(a, l)}{\partial l} } \\
& +\frac{\partial \gamma_{\mathbf{U}}^{I}(a, l)}{\partial l} \frac{1}{1-\delta(1-a)}\left[h^{I}\left(s c^{I}\right)-\Delta c\right] \\
& +\frac{\partial \gamma_{\mathbf{S}}^{I}(a, l)}{\partial l} \frac{1}{1-\delta(1-l)} h^{I}\left(s c^{I}\right)-\frac{\delta}{[1-\delta(1-l)]^{2}} \gamma_{\mathbf{S}}^{I}(a, l) h^{I}\left(s c^{I}\right)
\end{aligned}
$$

(A.30)

$$
\begin{aligned}
\frac{\partial B^{I *}(a, l)}{\partial a}= & {\left[-\frac{1}{1-\delta}+\frac{\gamma_{\mathbf{U}}^{I}}{1-\delta(1-a)}+\frac{\gamma_{\mathbf{S}}^{I}}{1-\delta(1-l)}\right] h^{I \prime}\left(s c^{I}\right) \frac{\partial s c^{I}(a, l)}{\partial a} } \\
& +\frac{\partial \gamma_{\mathbf{U}}^{I}(a, l)}{\partial a} \frac{1}{1-\delta(1-a)}\left[h^{I}\left(s c^{I}\right)-\Delta c\right]-\frac{\delta}{[1-\delta(1-a)]^{2}} \gamma_{\mathbf{U}}^{I}(a, l) \\
& \times\left[h^{I}\left(s c^{I}\right)-\Delta\right]+\frac{\partial \gamma_{\mathbf{S}}^{I}(a, l)}{\partial a} \frac{1}{1-\delta(1-l)} h^{I}\left(s c^{I}\right)
\end{aligned}
$$

Note that $-\frac{1}{1-\delta}+\frac{\gamma_{\mathrm{U}}^{I}}{1-\delta(1-a)}+\frac{\gamma_{\mathrm{s}}^{I}}{1-\delta(1-l)} \leq 0$ and $h^{I}\left(s c^{I}\right)-\Delta \leq 0$. Furthermore, from (A.24) $\frac{\partial \gamma_{\mathbf{U}}^{I}(a, l)}{\partial l}, \frac{\partial \gamma_{\mathbf{S}}^{I}(a, l)}{\partial a} \geq 0$ and $\frac{\partial \gamma_{\mathbf{S}}^{I}(a, l)}{\partial l}, \frac{\partial \gamma_{\mathbf{U}}^{I}(a, l)}{\partial a} \leq 0$. Thus, we have $\frac{\partial B^{I *}(a, l)}{\partial l} \leq$ 0 and $\frac{\partial B^{I *}(a, l)}{\partial a} \geq 0$ (with strict inequality whenever $s c^{I}(a, l) \in[0, \bar{c})$ ). 
A.8. Proofs of Propositions 7, 8, and 9. Note that the steady-state probabilities in the outsourcing are found as in (A.23) by substituting $\lambda^{I}(\mathbf{x})$ with $\lambda^{o}(\mathbf{x})$. If $\frac{\Delta c}{\bar{c}}$ is sufficiently large, then $s c^{o} \rightarrow 2 \bar{c}$, and $\lambda_{1}^{o}\left(M_{1} \mid a, l\right) \rightarrow 1$. Furthermore, as $s c^{o} \rightarrow$ $2 \bar{c}$, we have $\gamma_{\mathbf{U}}, \gamma_{\mathbf{s}}, \frac{\partial \gamma_{\mathbf{x}}^{o}}{\partial a}, \frac{\partial \gamma_{\mathbf{x}}^{o}}{\partial l} \rightarrow 0$. This means $\lim _{s c^{o} \rightarrow 2 \bar{c}} \frac{\partial S u_{i}^{o *}}{\partial a}=\left.\frac{1}{2} \frac{\partial S u_{1}\left(M_{1}\right)}{\partial a}\right|_{s c^{o}=2 \bar{c}}<0$, which follows from the fact that

$$
\begin{aligned}
\left.\frac{\partial S u_{1}\left(\mathbf{M}_{1}\right)}{\partial a}\right|_{s c^{o}=2 \bar{c}} & -\frac{\delta l}{[1-\delta(1-a)]^{2}[1-\delta(1-a)(1-l)]} \frac{\bar{c}}{6}+\frac{\delta(1-l)}{1-\delta(1-a)(1-l)} \\
& {\left[\frac{1}{1-\delta(1-l)}-\frac{1}{1-\delta(1-a)(1-l)}\left(3+\frac{\delta a(1-l)}{1-\delta(1-l)}+\frac{\delta l(1-a)}{1-\delta(1-a)}\right)\right] \frac{\bar{c}}{6} } \\
= & -\frac{\delta l}{[1-\delta(1-a)]^{2}[1-\delta(1-a)(1-l)]} \frac{\bar{c}}{6} \\
& +\frac{\delta(1-l)}{1-\delta(1-a)(1-l)}\left[\frac{1}{1-\delta(1-l)}-\frac{1}{1-\delta(1-a)(1-l)} \frac{\delta a(1-l)}{1-\delta(1-l)}\right. \\
= & -\frac{\delta}{[1-\delta(1-a)]^{2}[1-\delta(1-a)(1-l)]} \frac{\bar{c}}{6} \\
& -\frac{\delta l(1-a)}{[1-\delta(1-a)(1-l)]^{2}}\left(2+\frac{\delta l(1-a)}{1-\delta(1-a)}\right) \frac{\bar{c}}{6} \\
< & 0 .
\end{aligned}
$$

Since $\frac{\partial W^{o}\left(\mathbf{M}_{i}\right)}{\partial a}=-\frac{1}{1-\delta} h^{\prime}\left(s c^{o}\right) \frac{\partial s c^{o}}{\partial a}$, we have $\lim _{s c^{o} \rightarrow 2 \bar{c}} \frac{\partial W^{o *}}{\partial a}=\left.\frac{\partial W^{o}\left(\mathbf{M}_{1}\right)}{\partial a}\right|_{s c^{o}=2 \bar{c}}=$ 0 . Thus, $\lim _{s c^{o} \rightarrow 2 \bar{c}} \frac{\partial B^{o *}}{\partial a}=-\left.2 \frac{\partial S u_{1}^{o *}}{\partial a}\right|_{s c^{o}=2 \bar{c}}>0$. One can similarly show that $\lim _{s c^{o} \rightarrow 2 \bar{c}} \frac{\partial W^{o *}}{\partial l}=\left.\frac{\partial W^{o}\left(\mathbf{M}_{1}\right)}{\partial l}\right|_{s c^{o}=2 \bar{c}}=0$ and $\left.\frac{\partial S u_{1}\left(\mathbf{M}_{1}\right)}{\partial l}\right|_{s c^{o}=2 \bar{c}}<0$, which implies that $\lim _{s c^{o} \rightarrow 2 \bar{c}} \frac{\partial B^{o *}}{\partial l}=-\left.2 \frac{\partial S u_{1}^{o *}}{\partial l}\right|_{s c^{o}=2 \bar{c}}>0$.

For sufficiently small $\frac{\Delta c}{\bar{c}}$, we have $s c^{o}, \frac{\partial s c^{o}}{\partial a}, \frac{\partial s c^{o}}{\partial l} \rightarrow 0$, and $\lambda_{1}^{o}\left(\mathbf{M}_{1}\right) \rightarrow \frac{1}{2}$. This means switching cost has virtually no effect on the outsourcing buyer's decision, and thus the behavior is similar to the integrated buyer's. Thus, the proof of Proposition 7 follows similar lines to that of Proposition 6.

\section{APPENDIX B}

B.1. Managing Switching Costs with Learning Diffusion. Here we sketch the formal model with learning diffusion, and in the process prove Propositions 10 and 11. In addition to the assumptions of the outsourcing model, we now assume that the buyer can transfer her skill in one input to another with probability $\gamma \in[0,1]$. 
To prove the existence of a unique anonymous MPE, we first note that the equilibrium total surplus in (A.3) and the selection rule in (A.4) remain unchanged. What changes is the transition probabilities. To simplify the analysis, define $\widetilde{W}^{o}(\mathbf{M}) \equiv(1-\gamma) W^{o}(\mathbf{M})+\gamma W^{o}(\mathbf{S})$.

For $\mathbf{x}=\mathbf{S}$ and $\mathbf{U}$, since $s c^{o}=0, \sum_{\mathbf{x}^{\prime}} W^{o}\left(\mathbf{x}^{\prime}\right) \rho_{\mathbf{S x}^{\prime}}(1)=(1-l) W^{o}(\mathbf{S})+l \widetilde{W}^{o}(\mathbf{M})$, and $\sum_{\mathbf{x}^{\prime}} W^{o}\left(\mathbf{x}^{\prime}\right) \rho_{\mathbf{U x}^{\prime}}(1)=(1-a) W^{o}(\mathbf{U})+a \widetilde{W}^{o}(\mathbf{M}),($ A.3) implies

$$
\begin{aligned}
W^{o}(\mathbf{S}) & =\frac{v(s)-\frac{\bar{c}}{3}+\delta l \widetilde{W}^{o}(\mathbf{M})}{1-\delta(1-l)} \\
W^{o}(\mathbf{U}) & =\frac{v(u)-\frac{\bar{c}}{3}+\delta a \widetilde{W}^{o}(\mathbf{M})}{1-\delta(1-a)}
\end{aligned}
$$

Now consider $\mathbf{x}=\mathbf{M}_{1}$. From (A.7) and (A.8), we have

$$
W^{o}\left(\mathbf{M}_{1}\right)=v(s)-\frac{\bar{c}}{3}-h\left(s c^{o}\right)+\delta \widetilde{W}^{o}(\mathbf{M})
$$

Together (B.1), (B.2), (B.3), and $\widetilde{W}^{o}(\mathbf{M}) \equiv(1-\gamma) W^{o}(\mathbf{M})+\gamma W^{o}(\mathbf{S})$ reveal

$$
W^{o}\left(\mathbf{M}_{1}\right)=\frac{1}{1-\delta}\left\{v(s)-\frac{\bar{c}}{3}-\frac{1-\delta[(1-\gamma)(1-l)+\gamma]}{1-\delta(1-\gamma)(1-l)} h\left(s c^{o}\right)\right\}
$$

In addition, noting $\sum_{\mathbf{x}^{\prime}} W^{o}\left(\mathbf{x}^{\prime}\right) \rho_{\mathbf{x}^{\prime} \mathbf{M}_{1}}(1)=\widetilde{W^{o}}(\mathbf{M})$ and $\sum_{\mathbf{x}^{\prime}} W^{o}\left(\mathbf{x}^{\prime}\right) \rho_{\mathbf{M}_{1} \mathbf{x}^{\prime}}(1)=$ $[(1-a)(1-l)+a l] \widetilde{W^{o}}(\mathbf{M})+(1-a) l W^{o}(\mathbf{L})+a(1-l) W^{o}(\mathbf{H})$, and using (A.7), we also have

$$
W^{o}\left(\mathbf{M}_{1}\right)=\frac{1}{1-\delta}\left\{v(s)-\frac{\bar{c}}{3}-\frac{1-\delta[(1-\gamma)(1-l)+\gamma]}{(1-\gamma)[1-\delta(1-l)]} g\left(s c^{o}\right)\right\}
$$

where $h\left(s c^{o}\right) \equiv \frac{\left(s c^{o}\right)^{3}}{12 \bar{c}^{2}}-\frac{3\left(s c^{o}\right)^{2}}{8 \bar{c}}+\frac{s c^{o}}{2}$ and $g\left(s c^{o}\right) \equiv \frac{E-s c^{o}}{D}$ as defined above.

Combining (B.4) and (B.5), $s c^{o}$ solves the following equation:

$$
h(a)-k(\gamma) g(a)=0
$$

where $k(\gamma) \equiv \frac{1-\delta(1-\gamma)(1-l)}{(1-\gamma)[1-\delta(1-l)]}$ with these properties.

Properties of $k(\gamma)$ : (i) $k(\gamma)$ is strictly increasing in $\gamma$, (ii) $k(\gamma)>1$, (iii) $k(1)=$ $\infty$.

Note that with no learning diffusion, i.e., $\gamma=0$, (B.6) reduces to (A.11). To prove the existence of a nonnegative solution to (B.6), first suppose $E=0$. This means the unique root to (B.6) is $s c^{o}=0$. Now assume $E>0$. Since $h(0)-k(\gamma) g(0)=$ $-k(\gamma) \frac{E}{D}<0$ and $\lim _{s c^{o} \rightarrow \infty}\left[h\left(s c^{o}\right)-k(\gamma) g\left(s c^{o}\right)\right]=\infty$, there exists $s c^{o}>0$ that solves (B.6). Again, whenever $s c^{o}>2 \bar{c}$, we set $s c^{o}=2 \bar{c}$. Also since for any $s c^{o}<$ 0 , we have $h\left(s c^{o}\right)-k(\gamma) g\left(s c^{o}\right)<0$, there does not exist $s c^{o}<0$ that solves (B.6). 
Again, to guarantee the uniqueness we need some parameter restrictions like in Condition A. The solution to (B.6), and therefore the anonymous MPE, is unique if and only if one of the following conditions holds:

(1) $D \leq 16 k(\gamma)$ or

(2) if $D>16 k(\gamma)$, then either $\left.\left(\frac{3 D}{16}+\frac{3}{2} k(\gamma)\right) \bar{c}+\frac{D-16 k(\gamma)}{48 D} \sqrt{D[D-16 k(\gamma)}\right] \bar{c}-$ $k(\gamma) E<0$ or $\left(\frac{3 D}{16}+\frac{3}{2} k(\gamma)\right) \bar{c}-\frac{D-16 k(\gamma)}{48 D} \sqrt{D[D-16 k(\gamma)]} \bar{c}-k(\gamma) E>0$.

Thus, Condition $\mathrm{A}$ is also sufficient for uniqueness in this case, since $k(\gamma)>1$. From (B.6) and using properties of $k(\gamma)$, one can easily see that $\frac{\partial s c^{\circ}}{\partial \gamma}>0$, which also implies that $\frac{\partial \lambda_{1}^{o}\left(\mathbf{M}_{1}\right)}{\partial \gamma}=\left[\frac{1}{2 \bar{c}}-\frac{s c^{o}}{4 \bar{c}^{2}}\right] \frac{\partial s c^{o}}{\partial \gamma}>0$. The rest of Propositions 10 and 11 are proven similarly, albeit more tediously, as proofs of Propositions 7-9.

\section{REFERENCES}

Alchian, A., "Reliability of Progress Curve in Airframe Production," Econometrica 31 (1963), 679-93.

Anton, J., AND D. Yao, "Second Sourcing and Experience Curve: Price Competition in the Defense Procurement," Rand Journal of Economics 18 (1987), 57-76.

Appleyard, M., "Cooperative Knowledge Creation: The Case of Buyer-Supplier CoDevelopment in the Semiconductor Industry," Mimeo, University of Virginia, 2002.

Argote, L., S. Beckman, and D. Epple, "The Persistence and Transfer of Learning in Industrial Settings," Management Science 36 (1990), 140-54.

Asher, H., Cost-Quantity Relationships in the Airframe Industry, Report 291 (Santa Monica, CA: RAND Corporation, 1956).

Benkard, L., "Learning and Forgetting: The Dynamics of Aircraft Production," American Economic Review 90 (2000), 1034-54.

Bergemann, D., and J. Valimaki, "Learning and Strategic Pricing," Econometrica 64 (1996), 1125-50.

Boyer, M., And M. Moreaux, "Capacity Commitment versus Flexibility," Journal of Economics and Management Strategy 6 (1997), 347-76.

Burguet, R., "Optimal Repeated Purchases when Sellers Are Learning about Costs," Journal of Economic Theory 68 (1996), 440-55.

Cabral, L., And S. Greenstein, "Switching Costs and Bidding Parity in Government Procurement of Computer Systems," Journal of Law, Economics, and Organizations 6 (1990), 453-69.

- , AND M. Riordan, "The Learning Curve, Market Dominance, and Predatory Pricing," Econometrica 62 (1994), 1115-40.

— , AND J. M. VIllas-BoAs, "Bertrand Supertraps," Mimeo, University of California, Berkeley, 2004.

Darr, E., L. Argote, and D. Epple, "The Acquisition, Transfer, and Depreciation of Knowledge in Service Organizations: Productivity in Franchises," Management Science 41 (1995), 1750-62.

DAs VARMA, G., "Standard Auctions with Identity-Dependent Externalities," Rand Journal of Economics 33 (2002), 689-708.

Dudley, L., "Learning and Productivity Changes in Metal Products," American Economic Review 62 (1972), 662-69.

FARrell, J., AND P. Klemperer, "Coordination and Lock-in: Competition with Switching Costs and Network Effects," in M. Armstrong and R. Porter, eds., Handbook of Industrial Organization (Elsevier Science Publishers, 2004), forthcoming.

Fudenberg, D., And J. Tirole, Game Theory (Cambridge, MA: MIT Press, 1991). 
Greenstein, S., "Sole Source versus Competitive Bidding: US Government Agencies' Procedural Choice for Mainframe Computer Procurement, "Journal of Industrial Economics 43 (1995), 125-40.

_ See," Industrial and Corporate Change 6 (1997), 247-73.

Gruber, H., "Learning by Doing and Spillovers: Further Evidence for the Semiconductor Industry," Review of Industrial Organization 13 (1998), 697-711.

Hirsch, W., "Manufacturing Progress Functions," Review of Economics and Statistics 34 (1952), 143-55.

Jehiel, P., B. Moldovanu, and E. Stacchetti, "How (Not) to Sell Nuclear Weapons,"American Economic Review 86 (1996), 814-29.

,$- \ldots$, AND — - ,Multidimensional Mechanism Design for Auctions with Externalities," Journal of Economic Theory 85 (1999), 258-93.

Joskow, P., AND G. RozAnski, "The Effects of Learning by Doing on Nuclear Power Plant Operating Reliability," Review of Economics and Statistics 61 (1979), 161-68.

Keller, G., AND S. RAdY, "Optimal Experimentation in a Changing Environment," Review of Economic Studies 66 (1999), 475-507.

Kennan, J., "Repeated Bargaining with Persistent Private Information," Review of Economic Studies 68 (2001), 719-55.

Klein, B., R. Crawford, and A. Alchian, "Vertical Integration, Appropriable Rents, and the Competitive Contracting Process," Journal of Law and Economics 21 (1978), 297326.

KLEMPERER, P., "Markets with Switching Costs," Quarterly Journal of Economics 102 (1987), $375-94$.

_ _ "Competition when Consumers Have Switching Costs: An Overview with Applications to Industrial Organization, Macro Economics, and International Trade," Review of Economic Studies 62 (1995), 515-39.

Kovacic, W., And D. Smallwood, "Competition Policy, Rivalries, and Defense Industry Consolidation," Journal of Economic Perspectives 8 (1994), 91-110.

Laffont, J. J., AND J. Tirole, A Theory of Incentives in Procurement and Regulation (Cambridge, MA: MIT Press, 1993).

Lewis, T., AND H. YildiRim, "Managing Dynamic Competition," American Economic Review 92 (2002), 779-97.

Maskin, E., ANd J. Tirole, "Markov Perfect Equilibrium I: Observable Actions," Journal of Economic Theory 100 (2001), 191-219.

NyE, W., "Firm-Specific Learning by Doing in Semiconductor Production: Some Evidence from the 1986 Trade Agreement," Review of Industrial Organization 11 (1996), 383-94.

Rustichini, A., AND A. Wolinsky, "Learning about Variable Demand in the Long Run," Journal of Economic Dynamics and Control 19 (1995), 1283-92.

SEgAL, I., "Contracting with Externalities," Quarterly Journal of Economics 114 (1999), $337-88$.

TAYLOR, C., "Supplier Surfing: Competition and Consumer Behavior in Subscription Markets," Rand Journal of Economics 34 (2002), 223-46.

Williamson, O., Markets and Hierarchies: Analysis and Antitrust Implications (New York: Free Press, 1975).

Wright, T., "Factors Affecting the Cost of Airplanes," Journal of Aeronautical Sciences 3 (1936), 122-28.

Zimmerman, M., "Learning Effects and Commercialization of New Energy Technologies: The Care of Nuclear Power," Rand Journal of Economics 13 (1982), 297-310. 